\title{
Study of Anti-Cancer Properties of Thin Layers of Cadmium Oxide (CdO) Nanostructure
}

\section{Alireza Heidari ${ }^{1} 2^{\star}$, Jennifer Esposito ${ }^{1}$ and Angela Caissutti ${ }^{1}$}

${ }^{1}$ Faculty of Chemistry, California South University, USA

${ }^{2}$ American International Standards Institute, USA

\begin{abstract}
Thin layers of Cadmium Oxide ( $\mathrm{CdO}$ ) with various volumes of Cadmium acetate solution (60, 80 and $90 \mathrm{ml}$ ) were deposited using spray pyrolysis technique over a glassy substrate. Samples were investigated using FESEM images, XRD and UV-V is spectra as well as I-V characteristic. It was found that all samples were grown up with polycrystalline nanostructures along the preferred direction of (002). In addition, it was found that grew up samples in the volume of $80(\mathrm{ml})$ are of optimum anti-cancer properties condition in visible range regarding optimum structural (largest crystallite size and lowest crystallite defect density) and optical (smallest band gap and highest light absorption) conditions.
\end{abstract}

\section{Keywords}

Cadmium Oxide (CdO), Spray pyrolysis technique, Anti-cancer properties, Nanostructure, Visible light, Thin layers

\section{Introduction}

Cadmium Oxide ( $\mathrm{CdO})$ is one of the rare inherent semi-conductors of type $P$ with a narrow band gap of about 1.5-2.5 (eV) which has a monoclinic structure with limited transparency in the region of visible light [1-23]. Thin layers of this material are frequently dark brown to black. This darkness is due to narrow band gap and direct transitions between bands [24-84]. This fact leads to high absorption of visible light and can be used in optical pieces such as solar cells. In addition, this material is considered due to abundance of raw material, non-toxicity, easy production and ability to change and optimizing its physical properties using various physical and chemical methods such as chemical vapor deposition [85-127], spray pyrolysis [128153] and so on. This material is one of the important mineral oxides for applying in pieces such as solar cells, electrochromic pieces and gaseous sensors due to its availability, high absorption rate and low cost [154-183].

A good question is, "Why don't our bodies recognize and remove cancer cells as they would, say a bacteria or virus?" The answer is that most cancer cells are indeed detected and removed by our immune systems. Cells in our immune cells called natural killer cells have the job of finding cells that have become abnormal so that they

*Corresponding author: Alireza Heidari, Faculty of Chemistry, California South University, 14731 Comet St. Irvine, CA 92604; American International Standards Institute, Irvine, CA 3800, USA

Accepted: March 16, 2019; Published: March 18, 2019

Copyright: ( 2019 Heidari A, et al. This is an open-access article distributed under the terms of the Creative Commons Attribution License, which permits unrestricted use, distribution, and reproduction in any medium, provided the original author and source are credited.

Heidari et al. Int J Analyt Bioanalyt Methods 2019, 1:003 
can be removed by other cells in our immune system. Cancer cells remain alive either by evading detection or by inactivating the immune cells that come to the scene [146,184-195].

The ability of the immune system to recognize and eliminate cancer cells is thought to be responsible for the uncommon but welldocumented phenomena of some cancers going away without treatment of (the spontaneous remission of cancer). This process also lies at the crux of the new field of cancer treatment known as immunotherapy [196-200].

Precancerous cells may look abnormal and similar to cancer cells but are distinguished from cancer cells by their behavior. Unlike cancer cells, precancerous cells do not have the ability to spread (metastasize) to other regions of the body [191,197,201-208].

An often confusing condition is that of carcinoma-in-situ (CIS). Carcinoma in situ consists of cells with the abnormal changes found in cancer cells, but since they have not spread beyond their original location (or technically, have not gone beyond something called the basement membrane), they are not technically cancer. Since CIS can turn into cancer, it is usually treated as early cancer [209222].

In the current research, cost effective spray pyrolysis technique was used to investigate anticancer properties of Cadmium Oxide (CdO) thin layers with various volumes of spray solution.

\section{Samples Preparation}

To prepare thin layers of Cadmium Oxide (CdO), Cadmium acetate powder was solved in deionized water and 0.35 (M) Cadmium acetate solutions was prepared. Then, this solution was sprayed over glassy substrate in various volumes $(60,80,90$ $\mathrm{ml}$ ) - corresponding to samples of S1, S2, S3 - to prepare the considered layers. It is expected that in pyrolysis process, the following chemical reaction mechanism happens [5]: $\mathrm{H}_{2} \mathrm{O}$

$$
\mathrm{Cd}\left(\mathrm{CH}_{2} \mathrm{COO}\right)_{2} \cdot \mathrm{H}_{2} \mathrm{O}+\mathrm{H}_{2} \mathrm{O} \rightarrow \mathrm{CdO}+2 \mathrm{CH}_{3} \mathrm{COOH}+
$$

During each step, cleaned substrates were heated up to $570\left({ }^{\circ} \mathrm{C}\right)$ in spray device and then, solution was sprayed under air pressure (2.6 bar). In this process, distance of sprays from substrates was $55(\mathrm{~cm})$.
Structural analysis of samples was performed by X-Ray Diffraction (XRD) device (XRD; Brucker AXS) with CuK $\alpha$ spectral line emission (1.5405 Á) and the surface morphology of samples were investigated by Scanning Electron Microscopy (FESEM Hitachi S.4160). Optical characteristics of layers were measured using passed and absorbed spectra by optical spectroscopy (Shimadzu UV-Vis 1800) in the range of 200-1200 (nm).

\section{Surface Morphology}

Figure 1 shows SEM images of samples in
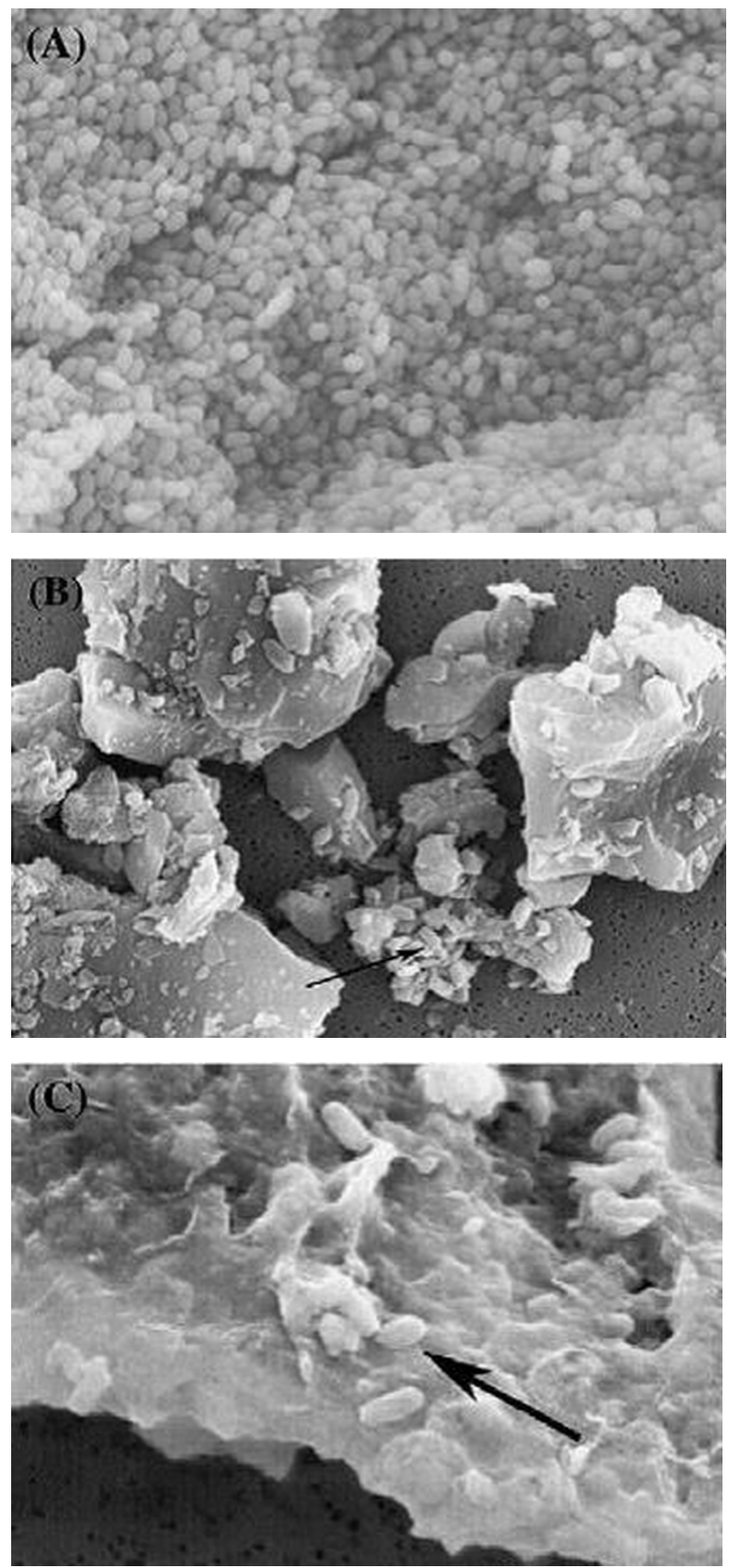

Figure 1: SEM images of thin layers of Cadmium Oxide (CdO) for samples prepared in various volumes. 


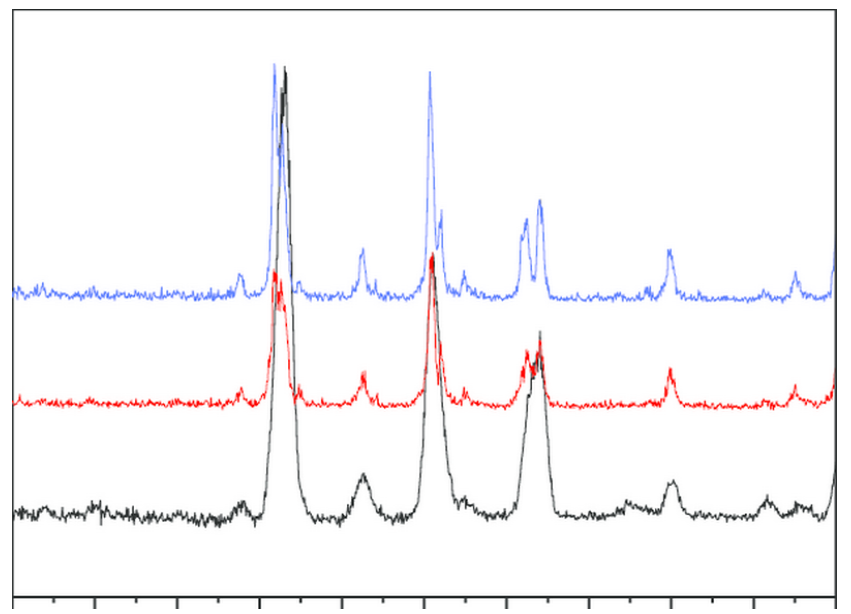

Figure 2: XRD spectrums of Cadmium Oxide (CdO) layers with various volumes of solution.

Table 1: Calculated structural and physical properties for the preferred peak (002).

\begin{tabular}{|l|l|l|l|}
\hline Sample & $\mathbf{D}(\mathbf{n m})$ & $\boldsymbol{\delta}\left(\times \mathbf{1 0}^{-\mathbf{2}} \mathbf{n m}^{-2}\right)$ & $\boldsymbol{\varepsilon}\left(\times \mathbf{1 0}^{-3}\right)$ \\
\hline S1 & 23.77 & 0.456 & 2.60 \\
\hline S2 & 39.63 & 0.237 & 2.79 \\
\hline S3 & 19.81 & 0.514 & 3.60 \\
\hline
\end{tabular}

the scales of 1 micron and $1000(\mathrm{~nm})$. Although the images for S1 and S3 samples show uniform surface along with some grains with 1 and 500 $(\mathrm{nm})$, respectively, S2 sample is of porous surface along with woven fibers and mud-like particles that differentiate it from two other samples.

\section{Structural and Physical Properties}

XRD spectrums of samples are shown in Figure 2. Diffraction curves of samples indicate that they are of polycrystalline structure with monoclinic structure and principal planes of (002) and (111) located at angles of $39.23^{\circ}$ and $43.84^{\circ}$. The results indicate that S2 sample with solution volume of 80 $(\mathrm{ml})$ is of weaker peaks at directions of (202) and (020) at angles of $58.91^{\circ}$ and $63.56^{\circ}$, respectively. The presence of these peaks along with relative intensity of the major peaks indicates that crystalline structure improves compared to other samples.

For more accurate investigation of structural properties, crystallite size (D), dislocation density $(\delta)$ and crystalline strains $(\varepsilon)$ are calculated [5]:

$$
\begin{aligned}
& D=0.9 \lambda / \beta \cos \theta \\
& \delta=1 / D^{2}
\end{aligned}
$$

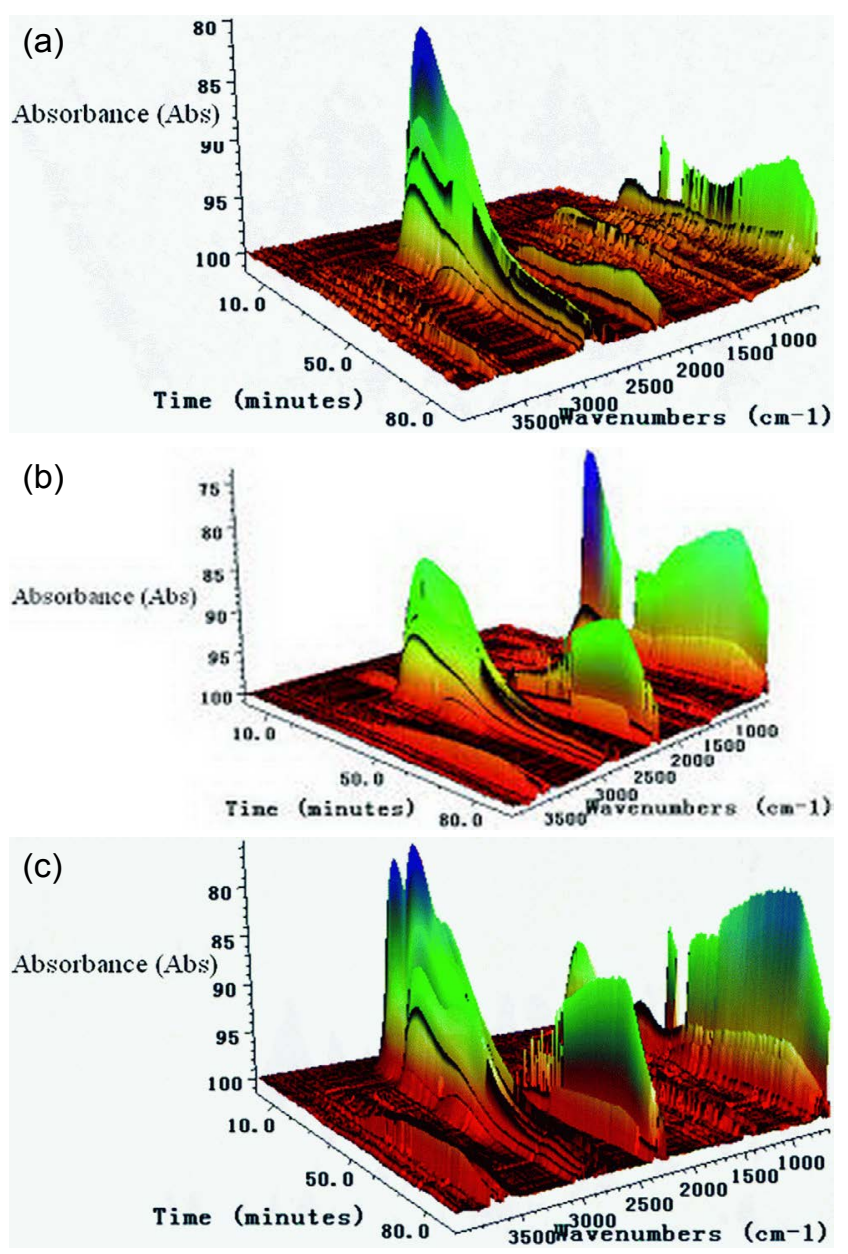

Figure 3: Passing optical absorption spectrums of Cadmium Oxide ( $\mathrm{CdO}$ ) thin layers grew up in various volumes.

$$
\varepsilon=\lambda / D \sin \theta-\beta / \tan \theta
$$

Where, $\beta$ is half width at full maximum, $D$ is crystallite size, $\theta$ is Brug angle and $\lambda$ is X-Ray wavelength. Results of these calculations are listed in Table 1.

\section{Optical Properties}

Figure 3 shows optical passing spectrum of the under studied layers. It can be seen that in visible region of 200-900 ( $\mathrm{nm})$, S2 sample and S3 sample are of the lowest and highest passing, respectively. These variations may be largely due to relative electrical conductivity of layers (Section 4) which is effective is relative amount of metal-like and or insulator-like of layers.

According to the reported results, Cadmium Oxide (CdO) layers are acted as a semiconductor with direct transition between bands so that during these transitions, absorption coefficient is a function 

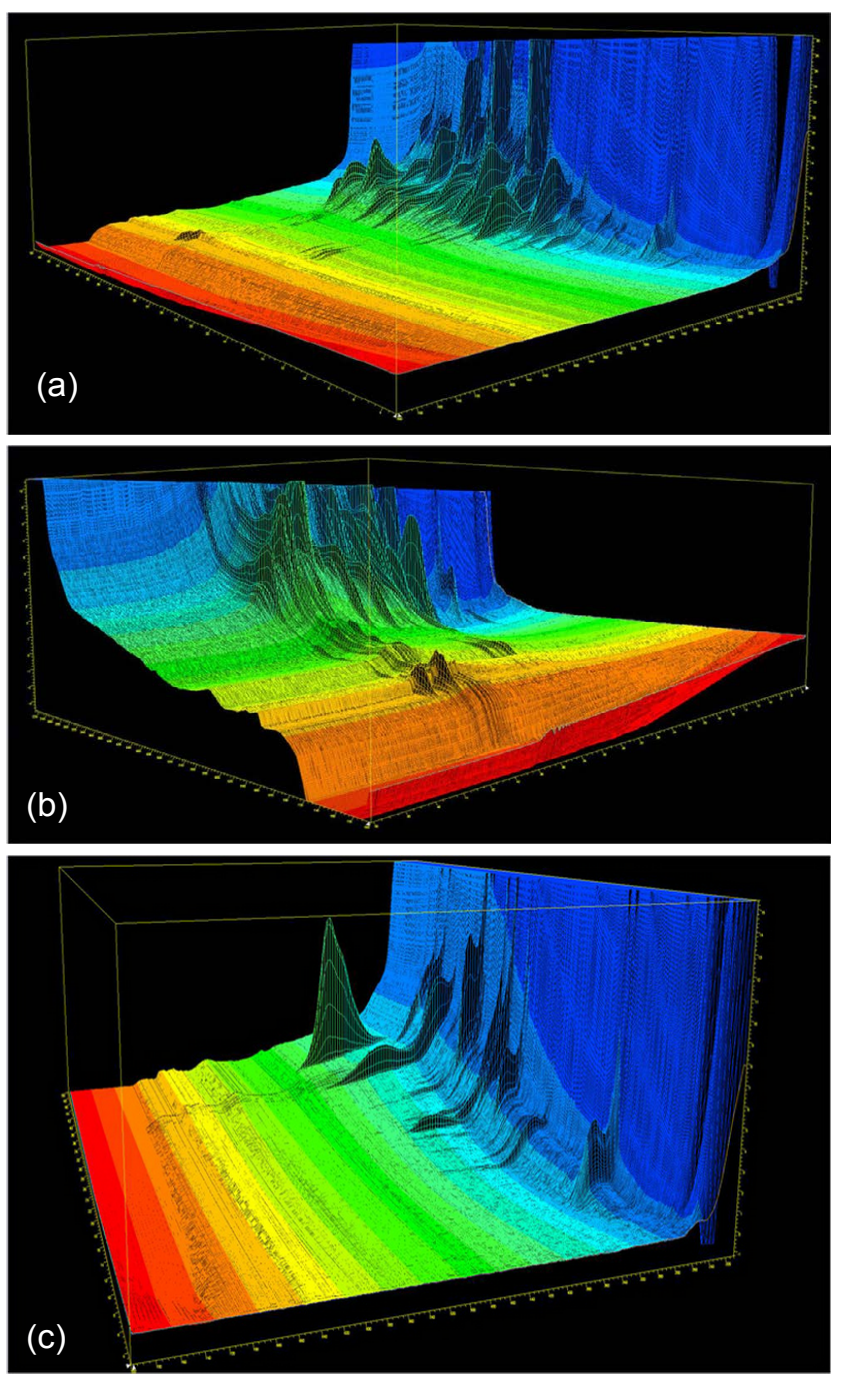

Figure 4: Absorption spectrums of under studied samples in terms of wavelength. of incident photon energy. Figure 4 shows the variations of absorption spectra of layers against wavelength.

Since Cadmium Oxide ( $\mathrm{CdO}$ ) is a semiconductor with direct transitions between bands, to determine optical band gap of samples, $(a h v)^{2}$ is drawn against hv and data is extrapolated in linear region of high energy with horizontal axis as $a=0$. Figure 5 shows this curve in order to determine direct optical band gap and the attached figure shows the results obtained from this analysis related to band gap amounts. The results indicate that the sample with largest crystallite size (S2) has the smallest band gap $(2.01 \mathrm{eV})$ and the sample with smallest crystallite size (S3) has the largest band gap (2.27 eV) which can be a reason for happening a quantum limitation in these samples.

\section{Electrical Properties}

Figure 6 shows current - voltage curve of these samples. The results indicate that sample $\mathrm{S} 2$ has the highest electrical conductivity (metal-like property) while sample S3 has the lowest one (isolator-like property). This is in good agreement with optical transition behavior of layers.

\section{Anti-Cancer Properties}

To investigate anti-cancer properties of samples, the under studied samples were placed under visible light emission (halogen lamp). Figure 7 shows current - voltage curve of samples under light. As
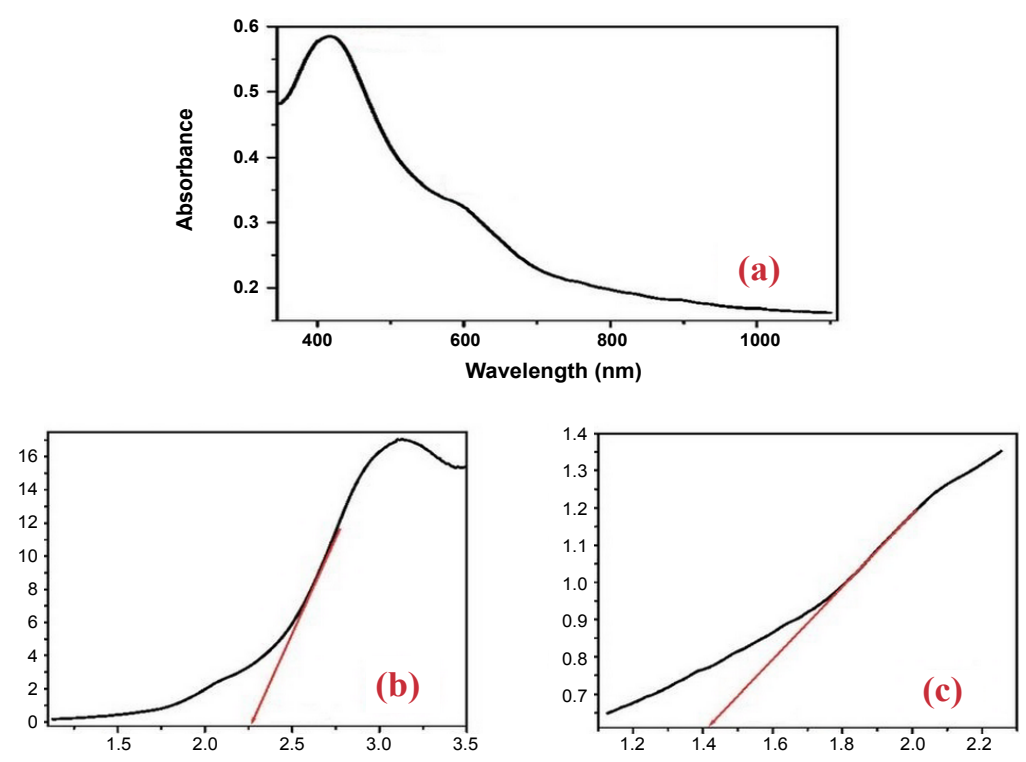

Figure 5: Analysis of optical spectrums data as a function of photon energy. The attached figure shows band gap of layers. 

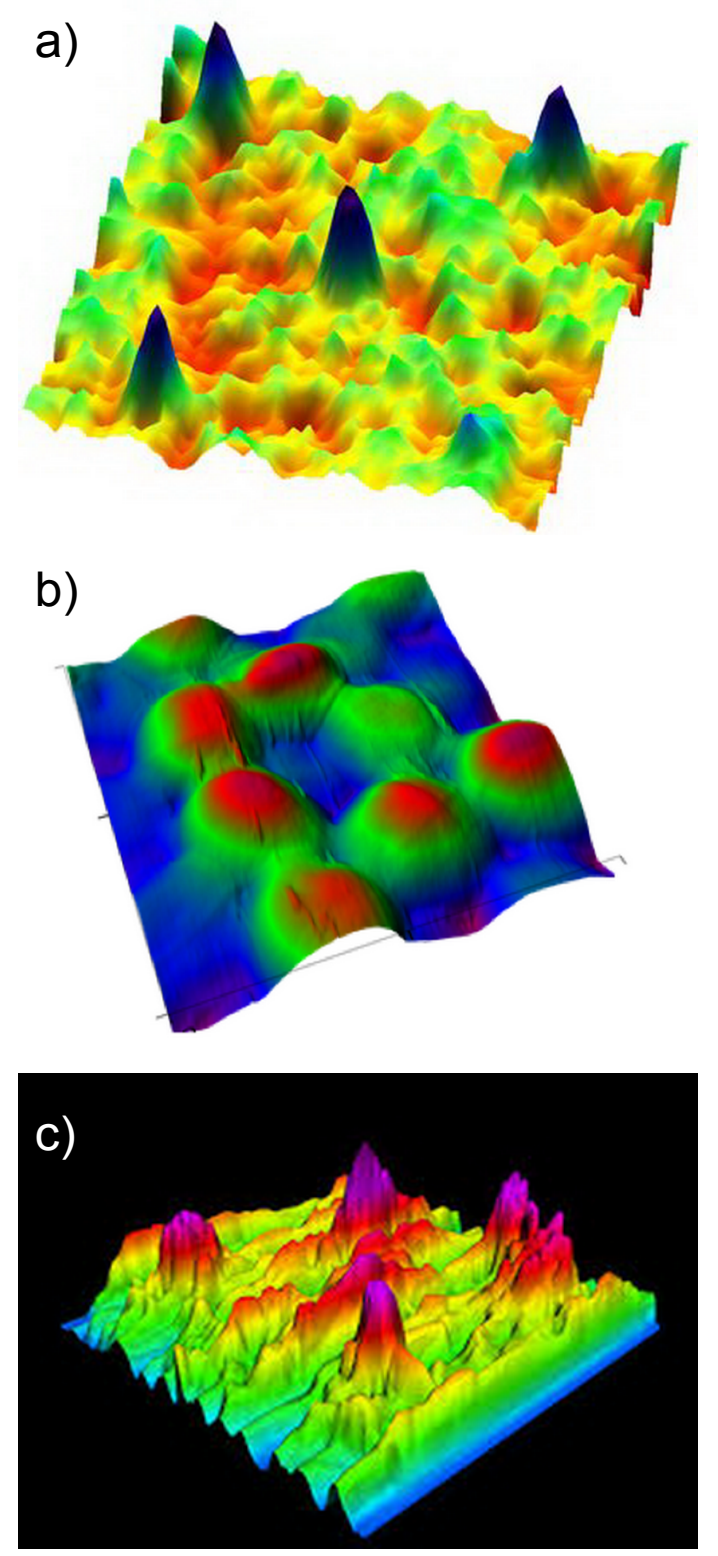

Figure 6: Current-voltage curve for samples grew up in darkness. can be observed, all three samples are reacted to the light and after emission, more electrical current passed through samples. This is an expected event due to producing electron - hole pairs in layers as a result of optical photon emission in $h v>E_{g}$. In order to compare optical sensitivity of these samples, the passed electrical current through samples in voltage of $4.5(\mathrm{~V})$ in darkness and under visible light emission are shown in Figure 8. As can be seen, sample S2 is of highest relative change of electrical current $\left(I_{\text {Light }} / I_{\text {Dark }}=15\right)$ and sample S3 is of lowest one (=7). These variations may be due to the effect of various factors such as optical absorption, band gap, crystallite size and crystalline obliquity in the investigated layer.

\section{Results and Discussion}

Cancer cells are usually formed after a series of mutations cause them to become increasingly abnormal. These mutations are either inherited or more often, caused by carcinogens (cancer-causing substances) in our environment. That cancer is caused by not one but several mutations explain why cancer is more common in older people and why it is often multifactorial (meaning there are several factors that work together to cause cancer). It also helps explain a genetic predisposition to cancer. A genetic predisposition does not mean you will get cancer, but, simplistically, if a few mutations are already in place, it will likely take fewer acquired mutations for a cell to become cancerous.

The process of normal cells becoming cancer often goes through stages in which the cell becomes progressively more abnormal appearing.

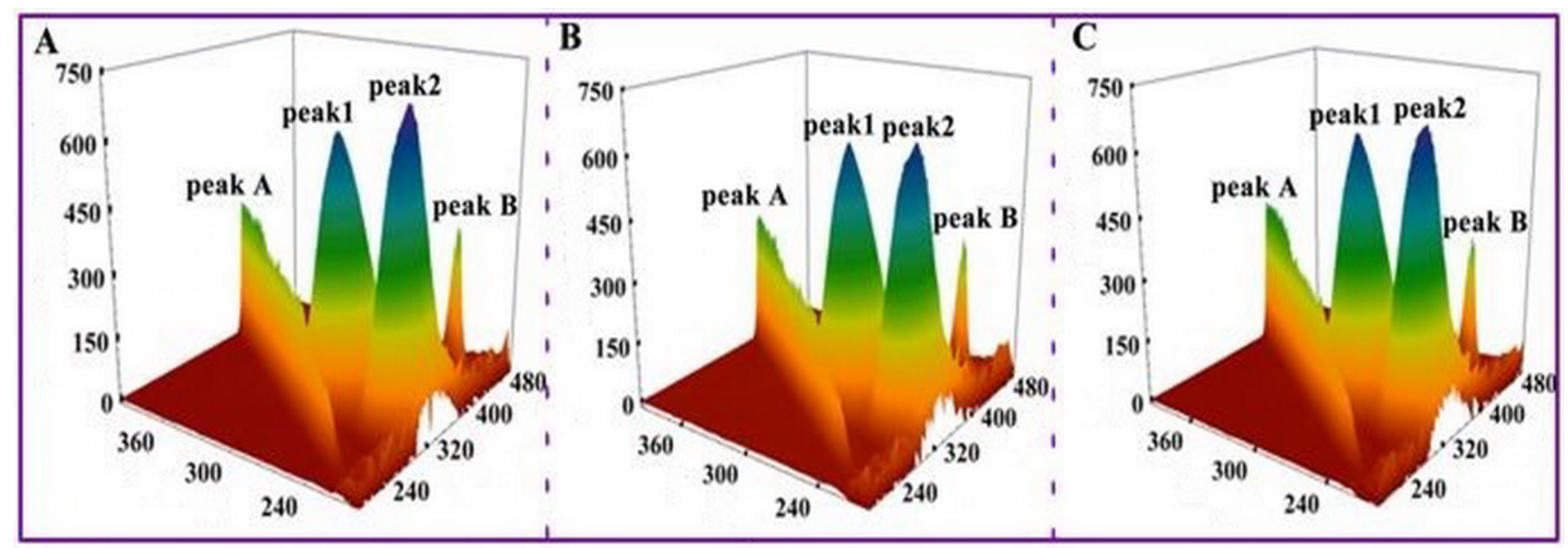

Figure 7: Current-voltage curve for samples subjected to visible light. 
a)

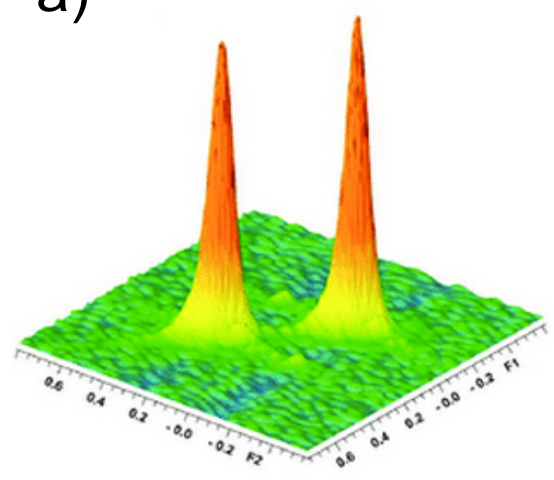

b)

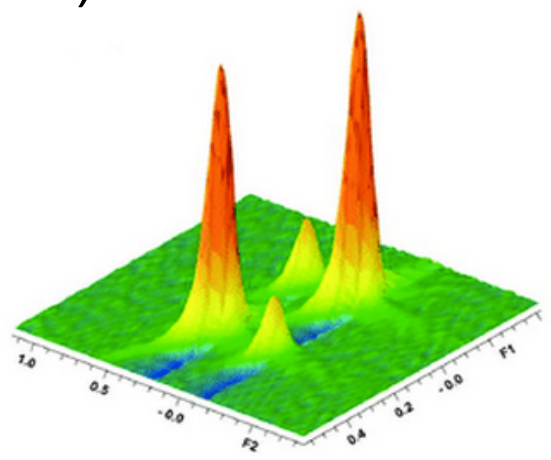

c)

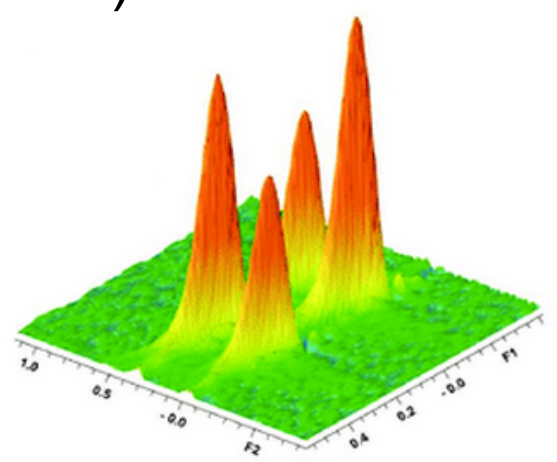

Figure 8: Passed electrical current through investigated samples.

These stages may include hyperplasia, dysplasia, and finally cancer. You may also hear this described as differentiation. Early on a cell may look much like normal cells of that organ or tissue, but as progression occurs, the cell becomes increasingly undifferentiated. This is, in fact, why sometimes the original source of cancer cannot be determined.

A cancer cell can have thousands of mutations, but only a certain number of these genetic changes in cancer cells cause cancer to divide and grow. Mutations which result in the growth of the cancer cells are referred to as "driver mutations", whereas other mutations are considered "passenger mutations". The term "oncogenes" refers to genes that drive the growth of cancer and give cancer its immortality. Tumor suppressor genes, in contrast, are genes within the cell which tell cells to slow down and stop growing, repair damaged DNA/ RNA, or tell cells when to die. Most cancer cells have mutations in both oncogenes and tumor suppressor genes which lead to their behavior.

\section{Conclusion and Summary}

The thin layers of Cadmium Oxide (CdO) nanostructures were deposited using spray pyrolysis technique with various volumes of spray solution over a glassy substrate. FESEM images indicate that surface morphology of samples are dependent on the variations of solution volume and XRD spectrum of layers indicate that polycrystalline structures are grew up in preferred direction of (002). Data analysis indicates that at solution volume of $80(\mathrm{ml})$, crystallite size and crystallite defect densities are optimum and anti-cancer properties are improved. In visible light region, layers are of low optical transition and of optical band gap between 2.01-2.27 (eV) so that sample S2 has the lowest band gap among all samples. The obtained results indicate that band gap variations in these samples are controlled by crystallite size and under the effect of happening a quantum limitation. Anti-cancer properties results indicate that sample $\mathbf{S 2}$ is of highest optical sensitivity to visible light.

\section{Acknowledgements}

Authors are supported by an American International Standards Institute (AISI) Future Fellowship Grant FT1201009373467. We acknowledge Ms. Isabelle Villena for instrumental support and Dr. Michael N. Cocchi for constructing Figure 1, Figure 2 and Figure 5. We gratefully acknowledge Prof. Dr. Christopher Brown for proof reading the manuscript.

\section{References}

1. A Heidari, C Brown (2015) Study of composition and morphology of cadmium oxide (cdo) nanoparticles for eliminating cancer cells. J Nanomed Res 2: 20.

2. A Heidari, C Brown (2015) Study of surface morphological, phytochemical and structural characteristics of Rhodium (III) Oxide $\left(\mathrm{Rh}_{2} \mathrm{O}_{3}\right)$ nanoparticles. International Journal of Pharmacology, Phytochemistry and Ethnomedicine 1: 15-19.

3. A Heidari (2016) An experimental biospectroscopic study on seminal plasma in determination of semen quality for evaluation of male infertility. Int J Adv Technol 7: e007.

4. A Heidari (2016) Extraction and preconcentration of $\mathrm{N}$-Tolyl-Sulfonyl-Phosphoramid-Saeure-Dichlorid as an anti-cancer drug from plants: A pharmacognosy study. J Pharmacogn Nat Prod 2: e103. 
5. A Heidari (2016) A thermodynamic study on hydration and dehydration of DNA and RNAamphiphile complexes. J Bioeng Biomed Sci S: 006.

6. A Heidari (2016) Computational studies on molecular structures and carbonyl and ketene groups effects of singlet and triplet energies of Azidoketene $\mathrm{O}=\mathrm{C}=\mathrm{CH}-\mathrm{NNN}$ and Isocyanatoketene $\mathrm{O}=\mathrm{C}=\mathrm{CH}$ $\mathrm{N}=\mathrm{C}=\mathrm{O}$. J Appl Computat Math 5: e142.

7. A Heidari (2016) Study of irradiations to enhance the induces the dissociation of hydrogen bonds between peptide chains and transition from helix structure to random coil structure using ATR-FTIR, Raman and ${ }^{1} \mathrm{HNMR}$ spectroscopies. J Biomol Res Ther 5: e146.

8. A Heidari (2016) Future prospects of point fluorescence spectroscopy, fluorescence imaging and fluorescence endoscopy in photodynamic therapy (PDT) for cancer cells. J Bioanal Biomed 8: e135.

9. A Heidari (2016) A bio-spectroscopic study of DNA density and color role as determining factor for absorbed irradiation in cancer cells. Adv Cancer Prev 1: e102.

10. A Heidari (2016) Manufacturing process of solar cells using cadmium oxide ( $\mathrm{CdO}$ ) and rhodium (III) oxide $\left(\mathrm{Rh}_{2} \mathrm{O}_{3}\right)$ nanoparticles. J Biotechnol Biomater 6: e125.

11. A Heidari (2016) A novel experimental and computational approach to photobiosimulation of telomeric DNA/RNA: A biospectroscopic and photobiological study. J Res Development 4: 144.

12. A Heidari (2016) Biochemical and pharmacodynamical study of microporous molecularly imprinted polymer selective for vancomycin, teicoplanin, oritavancin, telavancin and dalbavancin binding. Biochem Physiol 5: e146.

13. A Heidari (2016) Anti-cancer effect of UV irradiation at presence of cadmium oxide $(\mathrm{CdO})$ nanoparticles on dna of cancer cells: A photodynamic therapy study. Arch Cancer Res 4: 1.

14. A Heidari (2016) Biospectroscopic study on multicomponent reactions (MCRs) in two a-type and b-type conformations of nucleic acids to determine ligand binding modes, binding constant and stability of nucleic acids in cadmium oxide (CdO) nanoparticles-nucleic acids complexes as anticancer drugs. Arch Cancer Res 4: 2.

15. A Heidari (2016) Simulation of temperature distribution of DNA/RNA of human cancer cells using time-dependent bio-heat equation and $\mathrm{Nd}$ : YAG lasers. Arch Cancer Res 4: 2.
16. A Heidari (2016) Quantitative structure-activity relationship (QSAR) approximation for Cadmium Oxide (CdO) and Rhodium (III) Oxide $\left(\mathrm{Rh}_{2} \mathrm{O}_{3}\right)$ nanoparticles as anti-cancer drugs for the catalytic formation of proviral DNA from viral RNA using multiple linear and non-linear correlation approach. Ann Clin Lab Res 4: 1.

17. A Heidari (2016) Biomedical study of cancer cells DNA therapy using laser irradiations at presence of intelligent nanoparticles. J Biomedical Sci 5: 2.

18. A Heidari (2016) Measurement the amount of vitamin D2 (ergocalciferol), vitamin D3 (cholecalciferol) and absorbable calcium $\left(\mathrm{Ca}^{2+}\right)$, iron (II) $\left(\mathrm{Fe}^{2+}\right)$, magnesium $\left(\mathrm{Mg}^{2+}\right)$, phosphate $\left(\mathrm{PO}^{4-}\right.$ ) and zinc $\left(\mathrm{Zn}^{2+}\right)$ in apricot using high-performance liquid chromatography (HPLC) and spectroscopic techniques. J Biom Biostat 7: 292.

19. A Heidari (2016) Spectroscopy and quantum mechanics of the helium dimer $\left(\mathrm{He}^{2+}\right)$, neon dimer $\left(\mathrm{Ne}^{2+}\right)$, argon dimer $\left(\mathrm{Ar}^{2+}\right)$, krypton dimer $\left(\mathrm{Kr}^{2+}\right)$, xenon dimer $\left(\mathrm{Xe}^{2+}\right)$, radon dimer $\left(\mathrm{Rn}^{2+}\right)$ and ununoctium dimer $\left(\mathrm{UuO}^{2+}\right)$ molecular cations. Chem Sci J 7: e112.

20. A Heidari (2016) Human toxicity photodynamic therapy studies on DNA/RNA complexes as a promising new sensitizer for the treatment of malignant tumors using bio-spectroscopic techniques. J Drug Metab Toxicol 7: e129.

21. A Heidari (2016) Novel and stable modifications of intelligent cadmium oxide ( $\mathrm{CdO}$ ) nanoparticles as anti-cancer drug in formation of nucleic acids complexes for human cancer cells treatment. Biochem Pharmacol (Los Angel) 5: 207.

22. A Heidari (2016) A combined computational and $\mathrm{QM} / \mathrm{MM}$ molecular dynamics study on boron nitride nanotubes (BNNTs), amorphous boron nitride nanotubes (a-BNNTs) and hexagonal boron nitride nanotubes (h-BNNTs) as hydrogen storage. Struct Chem Crystallogr Commun 2: 1.

23. A Heidari (2016) Pharmaceutical and analytical chemistry study of cadmium oxide (CdO) nanoparticles synthesis methods and properties as anti-cancer drug and its effect on human cancer cells. Pharm Anal Chem Open Access 2: 113.

24. A Heidari (2016) A chemotherapeutic and biospectroscopic investigation of the interaction of double-standard DNA/RNA-binding molecules with cadmium oxide (CdO) and rhodium (III) oxide $\left(\mathrm{Rh}_{2} \mathrm{O}_{3}\right)$ nanoparticles as anti-cancer drugs for cancer cells' treatment. Chemo Open Access 5: e129. 
25. A Heidari (2016) Pharmacokinetics and experimental therapeutic study of DNA and other biomolecules using lasers: Advantages and applications. J Pharmacokinet Exp Ther 1: e005.

26. A Heidari (2016) Determination of ratio and stability constant of DNA/RNA in human cancer cells and cadmium oxide (cdo) nanoparticles complexes using analytical electrochemical and spectroscopic techniques. Insights Anal Electrochem 2: 1.

27. A Heidari (2016) Discriminate between antibacterial and non-antibacterial drugs artificial neutral networks of a multilayer perceptron (MLP) type using a set of topological descriptors. J Heavy Met Toxicity Dis 1: 2.

28. A Heidari (2016) Combined theoretical and computational study of the belousov-zhabotinsky chaotic reaction and curtius rearrangement for synthesis of mechlorethamine, cisplatin, streptozotocin, cyclophosphamide, melphalan, busulphan and benu as anti-cancer drugs. Insights Med Phys 1: 2.

29. A Heidari (2016) A translational biomedical approach to structural arrangement of amino acids' complexes: A combined theoretical and computational study. Transl Biomed 7: 2.

30. A Heidari (2016) Ab Initio and density functional theory (DFT) studies of dynamic nmr shielding tensors and vibrational frequencies of DNA/RNA and cadmium oxide ( $\mathrm{CdO}$ ) nanoparticles complexes in human cancer cells. J Nanomedine Biotherapeutic Discov 6: e144.

31. A Heidari (2016) Molecular dynamics and monte-carlo simulations for replacement sugars in insulin resistance, obesity, LDL cholesterol, triglycerides, metabolic syndrome, type 2 diabetes and cardiovascular disease: A glycobiological study. J Glycobiol 5: e111.

32. A Heidari (2016) Synthesis and study of 5-[(Phenylsulfonyl)Amino]-1,3,4-Thiadiazole-2Sulfonamide as potential anti-pertussis drug using chromatography and spectroscopy techniques. Transl Med (Sunnyvale) 6: e138.

33. A Heidari (2016) Nitrogen, oxygen, phosphorus and sulphur heterocyclic anti-cancer nano drugs separation in the supercritical fluid of ozone $\left(\mathrm{O}_{3}\right)$ using soave-redlich-kwong (SRK) and pang-robinson (PR) equations. Electronic J Biol 12: 4.

34. A Heidari (2016) An analytical and computational infrared spectroscopic review of vibrational modes in nucleic acids. Austin J Anal Pharm Chem 3: 1058.

35. A Heidari, C Brown (2016) Phase, composition and morphology study and analysis of Os-Pd/HfC nanocomposites. Nano Res Appl 2: 1.

36. A Heidari, C Brown (2016) Vibrational spectroscopic study of intensities and shifts of symmetric vibration modes of ozone diluted by cumene. International Journal of Advanced Chemistry 4: 5-9.

37. A Heidari (2016) Study of the role of anti-cancer molecules with different sizes for decreasing corresponding bulk tumor multiple organs or tissues. Arch Can Res 4: 2.

38. A Heidari (2016) Genomics and proteomics studies of zolpidem, necopidem, alpidem, saripidem, miroprofen, zolimidine, olprinone and abafungin as anti-tumor, peptide antibiotics, antiviral and central nervous system (CNS) drugs. J Data Mining Genomics \& Proteomics 7: e125.

39. A Heidari (2016) Pharmacogenomics and pharmacoproteomics studies of phosphodiesterase-5 (PDE5) inhibitors and paclitaxel albumin-stabilized nanoparticles as sandwiched anti-cancer nano drugs between two dna/rna molecules of human cancer cells. J Pharmacogenomics Pharmacoproteomics 7: e153.

40. A Heidari (2016) Biotranslational medical and biospectroscopic studies of cadmium oxide (CdO) Nanoparticles-DNA/RNA straight and cycle chain complexes as potent anti-viral, anti-tumor and anti-microbial drugs: A clinical approach. Transl Biomed 7: 2.

41. A Heidari (2016) A comparative study on simultaneous determination and separation of adsorbed cadmium oxide ( $\mathrm{CdO}$ ) nanoparticles on DNA/RNA of human cancer cells using biospectroscopic techniques and dielectrophoresis (DEP) method. Arch Can Res 4: 2.

42. A Heidari (2016) Cheminformatics and system chemistryof cisplatin, carboplatin, nedaplatin, oxaliplatin, heptaplatin and lobaplatin as anticancer nano drugs: A combined computational and experimental study. J Inform Data Min 1: 3.

43. A Heidari (2016) Linear and non-linear quantitative structure-anti-cancer-activity relationship (QSACAR) study of hydrous ruthenium (IV) oxide $\left(\mathrm{RuO}_{2}\right)$ nanoparticles as non-nucleoside reverse transcriptase inhibitors (NNRTIs) and anti-cancer nano drugs. J Integr Oncol 5: e110.

44. A Heidari (2016) Synthesis, characterization and biospectroscopic studies of cadmium oxide (CdO) nanoparticles-nucleic acids complexes absence of soluble polymer as a protective agent using nucleic 
acids condensation and solution reduction method. J Nanosci Curr Res 1: e101.

45. A Heidari (2016) Coplanarity and collinearity of 4'-Dinonyl-2,2'-Bithiazole in one domain of bleomycin and pingyangmycin to be responsible for binding of cadmium oxide ( $\mathrm{CdO}$ ) nanoparticles to DNA/RNA bidentate ligands as anti-tumor nano drug. Int J Drug Dev \& Res 8: 7-8.

46. A Heidari (2016) A pharmacovigilance study on linear and non-linear quantitative structure (chromatographic) retention relationships (QSRR) models for the prediction of retention time of anticancer nano drugs under synchrotron radiations. J Pharmacovigil 4: e161.

47. A Heidari (2016) Nanotechnology in preparation of semipermeable polymers. J Adv Chem Eng 6: 157.

48. A Heidari (2016) A gastrointestinal study on linear and non-linear quantitative structure (chromatographic) retention relationships (QSRR) models for analysis 5-aminosalicylates nano particles as digestive system nano drugs under synchrotron radiations. J Gastrointest Dig Syst 6: e119.

49. A Heidari (2016) DNA/RNA fragmentation and cytolysis in human cancer cells treated with diphthamide nano particles derivatives. Biomedical Data Mining 5: e102.

50. A Heidari (2016) A successful strategy for the prediction of solubility in the construction of quantitative structure-activity relationship (QSAR) and quantitative structure-property relationship (qspr) under synchrotron radiations using genetic function approximation (gfa) algorithm. J Mol Biol Biotechnol 1: 1.

51. A Heidari (2016) Computational study on molecular structures of $\mathrm{C}_{20}, \mathrm{C}_{60}, \mathrm{C}_{240}, \mathrm{C}_{540}, \mathrm{C}_{960}, \mathrm{C}_{2160}$ and $\mathrm{C}_{3840}$ fullerene nano molecules under synchrotron radiations using fuzzy logic. J Material Sci Eng 5: 282.

52. A Heidari (2016) Graph theoretical analysis of zigzag polyhexamethylene biguanide, polyhexamethylene adipamide, polyhexamethylene biguanide gauze and polyhexamethylene biguanide hydrochloride (PHMB) boron nitride nanotubes (BNNTs), amorphous boron nitride nanotubes (a-BNNTs) and hexagonal boron nitride nanotubes (h-BNNTs). J Appl Computat Math 5: e143.

53. A Heidari (2016) The impact of high resolution imaging on diagnosis. Int J Clin Med Imaging 3: 1000e101.

54. A Heidari (2016) A comparative study of confor- mational behavior of isotretinoin (13-Cis Retinoic Acid) and tretinoin (All-Trans Retinoic Acid (ATRA)) nano particles as anti-cancer nano drugs under synchrotron radiations using hartree-fock (HF) and density functional theory (DFT) methods. Insights in Biomed 1: 2.

55. A Heidari (2016) Advances in logic, operations and computational mathematics. J Appl Computat Math 5: 5.

56. A Heidari (2016) Mathematical equations in predicting physical behavior. J Appl Computat Math 5: 5.

57. A Heidari (2016) Chemotherapy a last resort for cancer treatment. Chemo Open Access 5: 4.

58. A Heidari (2016) Separation and pre-concentration of metal cations-dna/rna chelates using molecular beam mass spectrometry with tunable vacuum ultraviolet (VUV) synchrotron radiation and various analytical methods. Mass Spectrom Purif Tech 2: e101.

59. A Heidari (2016) Yoctosecond quantitative structure-activity relationship (QSAR) and quantitative structure-property relationship (QSPR) under synchrotron radiations studies for prediction of solubility of anti-cancer nano drugs in aqueous solutions using genetic function approximation (GFA) algorithm. Insight Pharm Res 1: 1.

60. A Heidari (2016) Cancer risk prediction and assessment in human cells under synchrotron radiations using quantitative structure activity relationship (QSAR) and quantitative structure properties relationship (QSPR) studies. Int J Clin Med Imaging 3: 516.

61. A Heidari (2016) A novel approach to biology. Electronic J Biol 12: 4.

62. A Heidari (2016) Innovative biomedical equipment's for diagnosis and treatment. J Bioengineer \& Biomedical Sci 6: 2.

63. A Heidari (2016) Integrating precision cancer medicine into healthcare, medicare reimbursement changes and the practice of oncology: Trends in oncology medicine and practices. J Oncol Med \& Pract 1: 2.

64. A Heidari (2016) Promoting convergence in biomedical and biomaterials sciences and silk proteins for biomedical and biomaterials applications: An introduction to materials in medicine and bioengineering perspectives. J Bioengineer \& Biomedical Sci 6: 3.

65. A Heidari (2017) X-Ray fluorescence and X-Ray diffraction analysis on discrete element modeling of nano powder metallurgy processes in optimal container design. J Powder Metall Min 6: 1. 
66. A Heidari (2017) Biomolecular spectroscopy and dynamics of nano-sized molecules and clusters as cross-linking-induced anti-cancer and immuneoncology nano drugs delivery in DNA/RNA of human cancer cells' membranes under synchrotron radiations: A payload-based perspective. Arch Chem Res 1: 2.

67. A Heidari (2017) Deficiencies in repair of doublestandard dna/rna-binding molecules identified in many types of solid and liquid tumors oncology in human body for advancing cancer immunotherapy using computer simulations and data analysis: Number of mutations in a synchronous tumor varies by age and type of synchronous cancer. J Appl Bioinforma Comput Biol 6: 1.

68. A Heidari (2017) Electronic coupling among the five nanomolecules shuts down quantum tunneling in the presence and absence of an applied magnetic field for indication of the dimer or other provide different influences on the magnetic behavior of single molecular magnets (SMMs) as qubits for quantum computing. Glob J Res Rev 4: 2.

69. A Heidari (2017) Polymorphism in nano-sized graphene ligand-induced transformation of $\mathrm{Au}_{38}-$ $\mathrm{xAg} \mathrm{x}_{\mathrm{x}} / \mathrm{xCu_{x }}(\mathrm{SPh}-\mathrm{tBu})_{24}$ to $\mathrm{Au}_{36}-\mathrm{xAg}_{\mathrm{x}} / \mathrm{xCu}_{\mathrm{x}}(\mathrm{SPh}-\mathrm{tBu})_{24}(\mathrm{x}$ $=1-12$ ) nanomolecules for synthesis of $\mathrm{Au}_{144^{-}}$ $\mathrm{xAg}_{\mathrm{x}} / \mathrm{xCu}_{\mathrm{x}}\left[(\mathrm{SR})_{60}, \quad\left(\mathrm{SC}_{4}\right)_{60}, \quad\left(\mathrm{SC}_{6}\right)_{60}, \quad\left(\mathrm{SC}_{12}\right)_{60}, \quad(\mathrm{PET})_{60^{\prime}}\right.$ $(\mathrm{p}-\mathrm{MBA})_{60^{\prime}}(\mathrm{F})_{60^{\prime}}(\mathrm{Cl})_{60^{\prime}}(\mathrm{Br})_{60^{\prime}}(\mathrm{I})_{60^{\prime}}(\mathrm{At})_{60^{\prime}}(\mathrm{Uus})_{60}$ and $\left.\left(\mathrm{SC}_{6} \mathrm{H}_{13}\right)_{60}\right]$ nano clusters as anti-cancer nano drugs. J Nanomater Mol Nanotechnol 6: 3.

70. A Heidari (2017) Biomedical resource oncology and data mining to enable resource discovery in medical, medicinal, clinical, pharmaceutical, chemical and translational research and their applications in cancer research. Int J Biomed Data Min 6: e103.

71. A Heidari (2017) Study of synthesis, pharmacokinetics, pharmacodynamics, dosing, stability, safety and efficacy of olympiadane nanomolecules as agent for cancer enzymotherapy, immunotherapy, chemotherapy, radiotherapy, hormone therapy and targeted therapy under synchrotorn radiation. J Dev Drugs 6: e154.

72. A Heidari (2017) A novel approach to future horizon of top seven biomedical research topics to watch in 2017: Alzheimer's, ebola, hypersomnia, human immunodeficiency virus (HIV), tuberculosis (TB), microbiome/antibiotic resistance and endovascular stroke. J Bioengineer \& Biomedical Sci 7: e127.

73. A Heidari (2017) Opinion on computational fluid dynamics (cfd) technique. Fluid Mech Open Acc 4: 157.
74. A Heidari (2017) Concurrent diagnosis of oncology influence outcomes in emergency general surgery for colorectal cancer and multiple sclerosis (MS) treatment using magnetic resonance imaging $(\mathrm{MRI})$ and $\mathrm{Au}_{329}(\mathrm{SR})_{84^{\prime}} \mathrm{Au}_{329-x} \mathrm{Ag}_{\mathrm{x}}(\mathrm{SR})_{84^{\prime}} \mathrm{Au}_{144}(\mathrm{SR})_{60^{\prime}}$ $\mathrm{Au}_{68}(\mathrm{SR})_{36}, \quad \mathrm{Au}_{30}(\mathrm{SR})_{18}, \quad \mathrm{Au}_{102}(\mathrm{SPh})_{44^{\prime}} \quad \mathrm{Au}_{38}(\mathrm{SPh})_{24^{\prime}}$ $\mathrm{Au}_{38}\left(\mathrm{SC}_{2} \mathrm{H}_{4} \mathrm{Ph}\right)_{24}, \mathrm{Au}_{21} \mathrm{~S}(\mathrm{SAdm})_{15}, \mathrm{Au}_{36}(\mathrm{pMBA})_{24}$ and $\mathrm{Au}_{25}(\mathrm{pMBA})_{18}$ nano clusters. J Surgery Emerg Med 1: 21.

75. A Heidari (2017) Developmental cell biology in adult stem cells death and autophagy to trigger a preventive allergic reaction to common airborne allergens under synchrotron radiation using nanotechnology for therapeutic goals in particular allergy shots (immunotherapy). Cell Biol (Henderson, NV) 6: 1.

76. A Heidari (2017) Changing metal powder characteristics for elimination of the heavy metals toxicity and diseases in disruption of extracellular matrix (ECM) proteins adjustment in cancer metastases induced by osteosarcoma, chondrosarcoma, carcinoid, carcinoma, ewing's sarcoma, fibrosarcoma and secondary hematopoietic solid or soft tissue tumors. J Powder Metall Min 6: 170.

77. A Heidari (2017) Nanomedicine-based combination anti-cancer therapy between nucleic acids and anticancer nano drugs in covalent nano drugs delivery systems for selective imaging and treatment of human brain tumors using hyaluronic acid, alguronic acid and sodium hyaluronate as anti-cancer nano drugs and nucleic acids delivery under synchrotron radiation. Am J Drug Deliv 5: 2.

78. A Heidari (2017) Clinical trials of dendritic cell therapies for cancer exposing vulnerabilities in human cancer cells' metabolism and metabolomics: New discoveries, unique features inform new therapeutic opportunities, biotech's bumpy road to the market and elucidating the biochemical programs that support cancer initiation and progression. J Biol Med Science 1: e103.

79. A Heidari (2017) The design graphene-based nanosheets as a new nanomaterial in anti-cancer therapy and delivery of chemotherapeutics and biological nano drugs for liposomal anti-cancer nano drugs and gene delivery. Br Biomed Bull 5: 305.

80. A Heidari (2017) Integrative approach to biological networks for emerging roles of proteomics, genomics and transcriptomics in the discovery and validation of human colorectal cancer biomarkers from DNA/RNA sequencing data under synchrotron radiation. Transcriptomics 5: e117. 
81. A Heidari (2017) Elimination of the heavy metals toxicity and diseases in disruption of extracellular matrix (ECM) proteins and cell adhesion intelligent nanomolecules adjustment in cancer metastases using metalloenzymes and under synchrotron radiation. Lett Health Biol Sci 2: 1-4.

82. A Heidari (2017) Treatment of breast cancer brain metastases through a targeted nanomolecule drug delivery system based on dopamine functionalized multi-wall carbon nanotubes (MWCNTs) coated with nano graphene oxide (GO) and protonated polyaniline (PANI) in situ during the polymerization of aniline autogenic nanoparticles for the delivery of anti-cancer nano drugs under synchrotron radiation. $\mathrm{Br} J$ Res 4: 16.

83. A Heidari (2017) Sedative, analgesic and ultrasoundmediated gastrointestinal nano drugs delivery for gastrointestinal endoscopic procedure, nano druginduced gastrointestinal disorders and nano drug treatment of gastric acidity. Res Rep Gastroenterol 1: 1.

84. A Heidari (2017) Synthesis, pharmacokinetics, pharmacodynamics, dosing, stability, safety and efficacy of orphan nano drugs to treat high cholesterol and related conditions and to prevent cardiovascular disease under synchrotron radiation. J Pharm Sci Emerg Drugs 5: 1.

85. A Heidari (2017) Design of targeted metal chelation therapeutics nanocapsules as colloidal carriers and blood-brain barrier (BBB) translocation to targeted deliver anti-cancer nano drugs into the human brain to treat alzheimer's disease under synchrotron radiation. J Nanotechnol Material Sci 4: 1-5.

86. R Gobato, A Heidari (2017) Calculations using quantum chemistry for inorganic molecule simulation BeLi ${ }_{2} \mathrm{SeSi}$. Science Journal of Analytical Chemistry 5: 76-85.

87. A Heidari (2017) Different high-resolution simulations of medical, medicinal, clinical, pharmaceutical and therapeutics oncology of human lung cancer translational anti-cancer nano drugs delivery treatment process under synchrotron and x-ray radiations. J Med Oncol 1: 1.

88. A Heidari (2017) A modern ethnomedicinal technique for transformation, prevention and treatment of human malignant gliomas tumors into human benign gliomas tumors under synchrotron radiation. Am J Ethnomed 4: 1-10.

89. A Heidari (2017) Active targeted nanoparticles for anti-cancer nano drugs delivery across the bloodbrain barrier for human brain cancer treatment, multiple sclerosis (MS) and alzheimer's diseases using chemical modifications of anti-cancer nano drugs or drug-nanoparticles through zika virus (ZIKV) nanocarriers under synchrotron radiation. J Med Chem Toxicol 2: 1-5.

90. A Heidari (2017) Investigation of medical, medicinal, clinical and pharmaceutical applications of estradiol, mestranol (norlutin), norethindrone (NET), norethisterone acetate (NETA), norethisterone enanthate (NETE) and testosterone nanoparticles as biological imaging, cell labeling, anti-microbial agents and anti-cancer nano drugs in nanomedicines based drug delivery systems for anti-cancer targeting and treatment. Parana Journal of Science and Education (PJSE) 3: 10-19.

91. A Heidari (2017) A comparative computational and experimental study on different vibrational biospectroscopy methods, techniques and applications for human cancer cells in tumor tissues simulation, modeling, research, diagnosis and treatment. Open J Anal Bioanal Chem 1: 014-020.

92. A Heidari (2017) Combination of DNA/RNA ligands and linear/non-linear visible-synchrotron radiation-driven n-doped ordered mesoporous cadmium oxide (CdO) nanoparticles photocatalysts channels resulted in an interesting synergistic effect enhancing catalytic anti-cancer activity. Enz Eng 6: 1.

93. A Heidari (2017) Modern approaches in designing ferritin, ferritin light chain, transferrin, beta-2 transferrin and bacterioferritin-based anti-cancer nano drugs encapsulating nanosphere as dnabinding proteins from starved cells (DPS). Mod Appro Drug Des 1: 1-5.

94. A Heidari (2017) Potency of human interferon $\beta-1 a$ and human interferon $\beta-1 b$ in enzymotherapy, immunotherapy, chemotherapy, radiotherapy, hormone therapy and targeted therapy of encephalomyelitis disseminate/multiple sclerosis (ms) and hepatitis A, B, C, D, E, F and G virus enter and targets liver cells. J Proteomics Enzymol 6: 1.

95. A Heidari (2017) Transport therapeutic active targeting of human brain tumors enable anti-cancer nanodrugs delivery across the blood-brain barrier (BBB) to treat brain diseases using nanoparticles and nanocarriers under synchrotron radiation. J Pharm Pharmaceutics 4: 1-5.

96. A Heidari, C Brown (2017) Combinatorial therapeutic approaches to DNA/RNA and benzylpenicillin (penicillin g), fluoxetine hydrochloride (prozac and sarafem), propofol (diprivan), acetylsalicylic acid (ASA) (Aspirin), naproxen sodium 
(aleve and naprosyn) and dextromethamphetamine nanocapsules with surface conjugated dna/ rna to targeted nano drugs for enhanced anti-cancer efficacy and targeted cancer therapy using nano drugs delivery systems. Ann Adv Chem 1: 061-069.

97. A Heidari (2017) High-resolution simulations of human brain cancer translational nano drugs delivery treatment process under synchrotron radiation. J Transl Res 1: 1-3.

98. A Heidari (2017) Investigation of anti-cancer nano drugs' effects' trend on human pancreas cancer cells and tissues prevention, diagnosis and treatment process under synchrotron and $\mathrm{X}$-ray radiations with the passage of time using mathematica. Current Trends Anal Bioanal Chem 1: 36-41.

99. A Heidari (2017) Pros and cons controversy on molecular imaging and dynamics of double-standard DNA/RNA of human preserving stem cells-binding nano molecules with androgens/anabolic steroids (AAS) or testosterone derivatives through tracking of helium-4 nucleus (Alpha Particle) using synchrotron radiation. Arch Biotechnol Biomed 1: 7-100.

100. A Heidari (2017) Visualizing metabolic changes in probing human cancer cells and tissues metabolism using vivo ${ }^{1} \mathrm{H}$ or Proton NMR, ${ }^{13} \mathrm{C}$ NMR, ${ }^{15} \mathrm{~N}$ NMR and ${ }^{31} \mathrm{P} N M R$ spectroscopy and self-organizing maps under synchrotron radiation. SOJ Mater Sci Eng 5: 1-6.

101.A Heidari (2017) Cavity ring-down spectroscopy (CRDS), circular dichroism spectroscopy, cold vapour atomic fluorescence spectroscopy and correlation spectroscopy comparative study on malignant and benign human cancer cells and tissues with the passage of time under synchrotron radiation. Enliven: Challenges Cancer Detect Ther 4: e001.

102.A Heidari (2017) Laser spectroscopy, laser-induced breakdown spectroscopy and laser-induced plasma spectroscopy comparative study on malignant and benign human cancer cells and tissues with the passage of time under synchrotron radiation. Int J Hepatol Gastroenterol 3: 079-084.

103.A Heidari (2017) Time-resolved spectroscopy and time-stretch spectroscopy comparative study on malignant and benign human cancer cells and tissues with the passage of time under synchrotron radiation. Enliven: Pharmacovigilance and Drug Safety 4: e001.

104.A Heidari (2017) Overview of the role of vitamins in reducing negative effect of Decapeptyl (Triptorelin Acetate or Pamoate Salts) on prostate cancer cells and tissues in prostate cancer treatment process through transformation of malignant prostate tumors into benign prostate tumors under synchrotron radiation. Open J Anal Bioanal Chem 1: 021-026.

105.A Heidari (2017) Electron Phenomenological Spectroscopy, Electron Paramagnetic Resonance (EPR) Spectroscopy and Electron Spin Resonance (ESR) Spectroscopy comparative study on malignant and benign human cancer cells and tissues with the passage of time under synchrotron radiation. Austin J Anal Pharm Chem 4: 1091.

106.A Heidari (2017) Therapeutic nanomedicine different high-resolution experimental images and computational simulations for human brain cancer cells and tissues using nanocarriers deliver DNA/ RNA to brain tumors under synchrotron radiation with the passage of time using mathematica and MATLAB. Madridge J Nano Tech Sci 2: 77-83.

107.A Heidari (2017) A consensus and prospective study on restoring Cadmium Oxide ( $\mathrm{CdO}$ ) nanoparticles sensitivity in recurrent ovarian cancer by extending the Cadmium Oxide (CdO) nanoparticles-free interval using synchrotron radiation therapy as antibody-drug conjugate for the treatment of limited-stage small cell diverse epithelial cancers. Cancer Clin Res Rep 1: e001.

108. A Heidari (2017) A novel and modern experimental imaging and spectroscopy comparative study on malignant and benign human cancer cells and tissues with the passage of time under white synchrotron radiation. Cancer Sci Res Open Access 4: 1-8.

109.A Heidari (2017) Different high-resolution simulations of medical, medicinal, clinical, pharmaceutical and therapeutics oncology of human breast cancer translational nano drugs delivery treatment process under synchrotron and X-Ray radiations. J Oral Cancer Res 1: 12-17.

110.A Heidari (2017) Vibrational Decihertz (dHz), Centihertz $(\mathrm{cHz})$, Millihertz $(\mathrm{mHz})$, Microhertz $(\mu \mathrm{Hz})$, Nanohertz $(\mathrm{nHz})$, Picohertz $(\mathrm{pHz})$, Femtohertz $(\mathrm{fHz})$, Attohertz $(\mathrm{aHz})$, Zeptohertz $(\mathrm{zHz})$ and Yoctohertz $(\mathrm{yHz})$ imaging and spectroscopy comparative study on malignant and benign human cancer cells and tissues under synchrotron radiation. International Journal of Biomedicine 7: 335-340.

111.A Heidari (2017) Force spectroscopy and fluorescence spectroscopy comparative study on malignant and benign human cancer cells and tissues with the passage of time under synchrotron radiation. EC Cancer 2: 239-246. 
112.A Heidari (2017) Photoacoustic spectroscopy, photoemission spectroscopy and photothermal spectroscopy comparative study on malignant and benign human cancer cells and tissues with the passage of time under synchrotron radiation. BAOJ Cancer Res Ther 3: 045-052.

113.A Heidari (2017) J-Spectroscopy, Exchange Spectroscopy (EXSY), Nuclear Overhauser Effect Spectroscopy (NOESY) and Total Correlation Spectroscopy (TOCSY) comparative study on malignant and benign human cancer cells and tissues under synchrotron radiation. EMS Eng Sci J 1: 006-013.

114.A Heidari (2017) Neutron spin echo spectroscopy and spin noise spectroscopy comparative study on malignant and benign human cancer cells and tissues with the passage of time under synchrotron radiation. Int J Biopharm Sci 1: 103-107.

115.A Heidari (2017) Vibrational Decahertz (daHz), Hectohertz $(\mathrm{hHz})$, Kilohertz $(\mathrm{kHz})$, Megahertz $(\mathrm{MHz})$, Gigahertz (GHz), Terahertz (THz), Petahertz (PHz), Exahertz (EHz), Zettahertz ( $\mathrm{ZHz})$ and Yottahertz $(\mathrm{YHz})$ imaging and spectroscopy comparative study on malignant and benign human cancer cells and tissues under synchrotron radiation. Madridge J Anal Sci Instrum 2: 41-46.

116. A Heidari (2018) Two-dimensional infrared correlation spectroscopy, linear two-dimensional infrared spectroscopy and non-linear two-dimensional infrared spectroscopy comparative study on malignant and benign human cancer cells and tissues under synchrotron radiation with the passage of time. J Mater Sci Nanotechnol 6: 101.

117.A Heidari (2018) Fourier Transform Infrared (FTIR) Spectroscopy, Near-Infrared Spectroscopy (NIRS) and Mid-Infrared Spectroscopy (MIRS) comparative study on malignant and benign human cancer cells and tissues under synchrotron radiation with the passage of time. Int J Nanotechnol Nanomed 3: 1-6.

118. A Heidari (2018) Infrared photo dissociation spectroscopy and infrared correlation table spectroscopy comparative study on malignant and benign human cancer cells and tissues under synchrotron radiation with the passage of time. Austin Pharmacol Pharm 3: 1011.

119.A Heidari (2017) Novel and transcendental prevention, diagnosis and treatment strategies for investigation of interaction among human blood cancer cells, tissues, tumors and metastases with synchrotron radiation under anti-cancer nano drugs delivery efficacy using MATLAB modeling and simulation. Madridge J Nov Drug Res 1: 18-24.
120.A Heidari (2018) Comparative study on malignant and benign human cancer cells and tissues with the passage of time under synchrotron radiation. Open Access J Trans Med Res 2: 4-9.

121.MRR Gobato, R Gobato, A Heidari (2018) Planting of jaboticaba trees for landscape repair of degraded area. Landscape Architecture and Regional Planning 3: 1-9.

122.A Heidari (2018) Fluorescence spectroscopy, phosphorescence spectroscopy and luminescence spectroscopy comparative study on malignant and benign human cancer cells and tissues under synchrotron radiation with the passage of time. SM J Clin Med Imaging 4: 1018.

123.A Heidari (2018) Nuclear Inelastic Scattering Spectroscopy (NISS) and Nuclear Inelastic Absorption Spectroscopy (NIAS) comparative study on malignant and benign human cancer cells and tissues under synchrotron radiation. Int J Pharm Sci 2: 1-14.

124. A Heidari (2018) X-Ray Diffraction (XRD), Powder $X$-Ray Diffraction (PXRD) and Energy-Dispersive X-Ray Diffraction (EDXRD) comparative study on malignant and benign human cancer cells and tissues under synchrotron radiation. J Oncol Res 2: 1-14.

125. A Heidari (2018) Correlation two-dimensional Nuclear Magnetic Resonance (NMR) (2D-NMR) (COSY) imaging and spectroscopy comparative study on malignant and benign human cancer cells and tissues under synchrotron radiation. EMS Can Sci.

126.A Heidari (2018) Thermal spectroscopy, photothermal spectroscopy, thermal microspectroscopy, photothermal microspectroscopy, thermal macrospectroscopy and photothermal macrospectroscopy comparative study on malignant and benign human cancer cells and tissues with the passage of time under synchrotron radiation. SM J Biometrics Biostat 3: 1024.

127.A Heidari (2018) A modern and comprehensive experimental biospectroscopic comparative study on human common cancers' cells, tissues and tumors before and after synchrotron radiation therapy. Open Acc J Oncol Med 1.

128. A Heidari (2018) Heteronuclear Correlation Experiments such as Heteronuclear Single-Quantum Correlation Spectroscopy (HSQC), Heteronuclear Multiple-Quantum Correlation Spectroscopy (HMQC) and Heteronuclear Multiple-Bond Correlation Spectroscopy (HMBC) comparative study on malignant and benign human endocrinology and thyroid cancer cells and tissues under synchrotron radiation. J Endocrinol Thyroid Res 3: 555603. 
129.A Heidari (2018) Nuclear Resonance Vibrational Spectroscopy (NRVS), Nuclear Inelastic Scattering Spectroscopy (NISS), Nuclear Inelastic Absorption Spectroscopy (NIAS) and Nuclear Resonant Inelastic X-Ray Scattering Spectroscopy (NRIXSS) comparative study on malignant and benign human cancer cells and tissues under synchrotron radiation. Int J Bioorg Chem Mol Biol 6: 1-5.

130. A Heidari (2018) A novel and modern experimental approach to vibrational circular dichroism spectroscopy and video spectroscopy comparative study on malignant and benign human cancer cells and tissues with the passage of time under white and monochromatic synchrotron radiation. Glob J Endocrinol Metab 1.

131. A Heidari (2018) Pros and Cons Controversy on heteronuclear correlation experiments such as Heteronuclear Single-Quantum Correlation Spectroscopy (HSQC), Heteronuclear Multiple-Quantum Correlation Spectroscopy (HMQC) and Heteronuclear Multiple-Bond Correlation Spectroscopy (HMBC) comparative study on malignant and benign human cancer cells and tissues under synchrotron radiation. EMS Pharma J 1: 002-008.

132. A Heidari (2018) A modern comparative and comprehensive experimental biospectroscopic study on different types of infrared spectroscopy of malignant and benign human cancer cells and tissues with the passage of time under synchrotron radiation. J Analyt Molecul Tech 3: 8.

133. A Heidari (2048) Investigation of cancer types using synchrotron technology for proton beam therapy: An experimental biospectroscopic comparative study. European Modern Studies Journal 2: 13-29.

134.A Heidari (2018) Saturated spectroscopy and unsaturated spectroscopy comparative study on malignant and benign human cancer cells and tissues with the passage of time under synchrotron radiation. Imaging J Clin Medical Sci 5: 001-007.

135.A Heidari (2018) Small-Angle Neutron Scattering (SANS) and Wide-Angle X-Ray Diffraction (WAXD) comparative study on malignant and benign human cancer cells and tissues under synchrotron radiation. Int J Bioorg Chem Mol Biol 6: 1-6.

136. A Heidari (2018) Investigation of bladder cancer, breast cancer, colorectal cancer, endometrial cancer, kidney cancer, leukemia, liver, lung cancer, melanoma, non-hodgkin lymphoma, pancreatic cancer, prostate cancer, thyroid cancer and non-melanoma skin cancer using synchrotron technology for proton beam therapy: An experimental biospectroscopic comparative study. Ther Res Skin Dis 1.

137.A Heidari (2018) Attenuated Total Reflectance FourierTransform Infrared (ATR-FTIR) Spectroscopy, Micro-Attenuated Total Reflectance Fourier Transform Infrared (Micro-ATR-FTIR) Spectroscopy and Macro-Attenuated Total Reflectance Fourier Transform Infrared (Macro-ATR-FTIR) spectroscopy comparative study on malignant and benign human cancer cells and tissues under synchrotron radiation with the passage of time. International Journal of Chemistry Papers 2: 1-12.

138.A Heidari (2018) Mössbauer spectroscopy, mössbauer emission spectroscopy and ${ }^{57} \mathrm{Fe}$ mössbauer spectroscopy comparative study on malignant and benign human cancer cells and tissues under synchrotron radiation. Acta Scientific Cancer Biology 2.3: 17-20.

139.A Heidari (2018) Comparative study on malignant and benign human cancer cells and tissues under synchrotron radiation with the passage of time. Organic \& Medicinal Chem IJ 6: 555676.

140.A Heidari (2018) Correlation spectroscopy, exclusive correlation spectroscopy and total correlation spectroscopy comparative study on malignant and benign human aids-related cancers cells and tissues with the passage of time under synchrotron radiation. Int J Bioanal Biomed 2: 001-007.

141.A Heidari (2018) Biomedical instrumentation and applications of biospectroscopic methods and techniques in malignant and benign human cancer cells and tissues studies under synchrotron radiation and anti-cancer nano drugs delivery. Am J Nanotechnol Nanomed 1: 001-009.

142.A Heidari (2018) Vivo ${ }^{1} \mathrm{H}$ or Proton NMR, ${ }^{13} \mathrm{C}$ NMR, ${ }^{15} \mathrm{~N}$ NMR and ${ }^{31} \mathrm{P}$ NMR spectroscopy comparative study on malignant and benign human cancer cells and tissues under synchrotron radiation. Ann Biomet Biostat 1: 1001.

143.A Heidari (2018) Grazing-Incidence Small-Angle Neutron Scattering (GISANS) and Grazing-Incidence X-Ray Diffraction (GIXD) comparative study on malignant and benign human cancer cells, tissues and tumors under synchrotron radiation. Ann Cardiovasc Surg 1: 1006.

144.A Heidari (2018) Adsorption Isotherms and Kinetics of Multi-Walled Carbon Nanotubes (MWCNTs), Boron Nitride Nanotubes (BNNTs), Amorphous Boron Nitride Nanotubes (a-BNNTs) and Hexagonal Boron Nitride Nanotubes (h-BNNTs) for eliminating carcinoma, sarcoma, lymphoma, leukemia, germ 
cell tumor and blastoma cancer cells and tissues. Clin Med Rev Case Rep 5: 201.

145.A Heidari (2018) Correlation Spectroscopy (COSY), Exclusive Correlation Spectroscopy (ECOSY), Total Correlation Spectroscopy (TOCSY), Incredible Natural-Abundance Double-Quantum Transfer Experiment (INADEQUATE), Heteronuclear Single-Quantum Correlation Spectroscopy (HSQC), Heteronuclear Multiple-Bond Correlation Spectroscopy (HMBC), Nuclear Overhauser Effect Spectroscopy (NOESY) and Rotating Frame Nuclear Overhauser Effect Spectroscopy (ROESY) comparative study on malignant and benign human cancer cells and tissues under synchrotron radiation. Acta Scientific Pharmaceutical Sciences 2: 30-35.

146.A Heidari (2018) Small-Angle X-Ray Scattering (SAXS), Ultra-Small Angle X-Ray Scattering (USAXS), Fluctuation X-Ray Scattering (FXS), Wide-Angle $X$-Ray Scattering (WAXS), Grazing-Incidence SmallAngle X-Ray Scattering (GISAXS), Grazing-Incidence Wide-Angle X-Ray Scattering (GIWAXS), SmallAngle Neutron Scattering (SANS), Grazing-Incidence Small-Angle Neutron Scattering (GISANS), X-Ray Diffraction (XRD), Powder X-Ray Diffraction (PXRD), Wide-Angle X-Ray Diffraction (WAXD), GrazingIncidence X-Ray Diffraction (GIXD) and EnergyDispersive X-Ray Diffraction (EDXRD) comparative study on malignant and benign human cancer cells and tissues under synchrotron radiation. Oncol Res Rev 1: 1-10.

147.A Heidari (2018) Pump-probe spectroscopy and transient grating spectroscopy comparative study on malignant and benign human cancer cells and tissues with the passage of time under synchrotron radiation. Adv Material Sci Engg 2: 1-7.

148.A Heidari (2018) Grazing-Incidence Small-Angle $X$-Ray Scattering (GISAXS) and Grazing-Incidence Wide-Angle X-Ray Scattering (GIWAXS) comparative study on malignant and benign human cancer cells and tissues under synchrotron radiation. Insights Pharmacol Pharm Sci 1: 1-8.

149.A Heidari (2018) Acoustic spectroscopy, acoustic resonance spectroscopy and auger spectroscopy comparative study on anti-cancer nano drugs delivery in malignant and benign human cancer cells and tissues with the passage of time under synchrotron radiation. Nanosci Technol 5: 1-9.

150.A Heidari (2018) Niobium, Technetium, Ruthenium, Rhodium, Hafnium, Rhenium, Osmium and Iridium Ions Incorporation into the Nano Polymeric Matrix (NPM) by Immersion of the Nano Polymeric Modified Electrode (NPME) as molecular enzymes and drug targets for human cancer cells, tissues and tumors treatment under synchrotron and synchrocyclotron radiations. Nanomed Nanotechnol 3: 000138.

151. A Heidari (2018) Homonuclear Correlation Experiments such as Homonuclear Single-Quantum Correlation Spectroscopy (HSQC), Homonuclear Multiple-Quantum Correlation Spectroscopy (HMQC) and Homonuclear Multiple-Bond Correlation Spectroscopy (HMBC) comparative study on malignant and benign human cancer cells and tissues under synchrotron radiation. Austin J Proteomics Bioinform \& Genomics 5: 1024.

152.A Heidari (2018) Atomic Force Microscopy Based Infrared (AFM-IR) spectroscopy and nuclear resonance vibrational spectroscopy comparative study on malignant and benign human cancer cells and tissues under synchrotron radiation with the passage of time. J Appl Biotechnol Bioeng 5: 142148.

153.A Heidari (2018) Time-dependent vibrational spectral analysis of malignant and benign human cancer cells and tissues under synchrotron radiation. J Cancer Oncol 2: 000124.

154.A Heidari (2018) Palauamine and olympiadane nano molecules incorporation into the Nano Polymeric Matrix (NPM) by immersion of the Nano Polymeric Modified Electrode (NPME) as molecular enzymes and drug targets for human cancer cells, tissues and tumors treatment under synchrotron and synchrocyclotron radiations. Arc Org Inorg Chem Sci 3.

155.R Gobato, A Heidari (2018) Infrared spectrum and sites of action of sanguinarine by molecular mechanics and ab initio methods. International Journal of Atmospheric and Oceanic Sciences 2: 1-9.

156.A Heidari (2018) Angelic acid, diabolic acids, draculin and miraculin nano molecules incorporation into the Nano Polymeric Matrix (NPM) by Immersion of the Nano Polymeric Modified Electrode (NPME) as molecular enzymes and drug targets for human cancer cells, tissues and tumors treatment under synchrotron and synchrocyclotron radiations. Med \& Analy Chem Int J 2: 000111.

157.A Heidari (2018) Gamma Linolenic Methyl Ester, 5-Heptadeca-5,8,11-Trienyl 1,3,4-Oxadiazole-2-Thiol, Sulphoquinovosyl Diacyl Glycerol, Ruscogenin, Nocturnoside B, Protodioscine B, Parquisoside-B, Leiocarposide, Narangenin, 7-Methoxy Hespertin, Lupeol, Rosemariquinone, Rosmanol and Rosemadiol Nano Molecules Incorporation into the Nano Polymeric Matrix (NPM) by Immersion of the Nano 
Polymeric Modified Electrode (NPME) as molecular enzymes and drug targets for human cancer cells, tissues and tumors treatment under synchrotron and synchrocyclotron radiations. Int J Pharma Anal Acta 2: 007-014.

158. A Heidari (2018) Fourier Transform Infrared (FTIR) Spectroscopy, Attenuated Total Reflectance Fourier Transform Infrared (ATR-FTIR) Spectroscopy, Micro-Attenuated Total Reflectance Fourier Transform Infrared (Micro-ATR-FTIR) Spectroscopy, Macro-Attenuated Total Reflectance Fourier Transform Infrared (Macro-ATR-FTIR) Spectroscopy, two-dimensional infrared correlation spectroscopy, linear two-dimensional infrared spectroscopy, non-linear two-dimensional infrared spectroscopy, Atomic Force Microscopy Based Infrared (AFM-IR) spectroscopy, infrared photodissociation spectroscopy, infrared correlation table spectroscopy, Near-Infrared Spectroscopy (NIRS), Mid-Infrared Spectroscopy (MIRS), nuclear resonance vibrational spectroscopy, thermal infrared spectroscopy and photothermal infrared spectroscopy comparative study on malignant and benign human cancer cells and tissues under synchrotron radiation with the passage of time. Glob Imaging Insights 3: 1-14.

159.A Heidari (2018) Heteronuclear Single-Quantum Correlation Spectroscopy (HSQC) and Heteronuclear Multiple-Bond Correlation Spectroscopy (HMBC) comparative study on malignant and benign human cancer cells, tissues and tumors under synchrotron and synchrocyclotron radiations. Chronicle of Medicine and Surgery 2: 144-156.

160.A Heidari (2018) Tetrakis [3, 5-bis (Trifluoromethyl) Phenyl] Borate (BARF)-Enhanced Precatalyst Preparation Stabilization and Initiation (EPPSI) Nano Molecules. Medical Research and Clinical Case Reports 2: 113-126.

161.A Heidari (2018) Sydnone, münchnone, montréalone, mogone, montelukast, quebecol and palau'amine-Enhanced Precatalyst Preparation Stabilization and Initiation (EPPSI) Nano Molecules. Sur Cas Stud Op Acc J 1.

162. A Heidari (2018) Fornacite, orotic acid, rhamnetin, Sodium Ethyl Xanthate (SEX) and spermine (spermidine or polyamine) nanomolecules incorporation into the Nanopolymeric Matrix (NPM). International Journal of Biochemistry and Biomolecules 4: 1-19.

163.A Heidari, R Gobato (2018) Putrescine, cadaverine, spermine and Spermidine-Enhanced Precatalyst Preparation Stabilization and Initiation (EPPSI) nano molecules. Parana Journal of Science and Education (PJSE) 4: 1-14.
164.A Heidari (2018) Cadaverine (1,5-Pentanediamine or Pentamethylenediamine), Diethyl Azodicarboxylate (DEAD or DEADCAT) and Putrescine (Tetramethylenediamine) Nano Molecules Incorporation into the Nano Polymeric Matrix (NPM) by Immersion of the Nano Polymeric Modified Electrode (NPME) as Molecular Enzymes and Drug Targets for Human Cancer Cells, Tissues and Tumors Treatment under Synchrotron and Synchrocyclotron Radiations. Hiv and Sexual Health Open Access Open Journal 1: 4-11.

165.A Heidari (2018) Improving the performance of nano-endofullerenes in polyaniline nanostructurebased biosensors by covering californium colloidal nanoparticles with multi-walled carbon nanotubes. Journal of Advances in Nanomaterials 3: 1-28.

166.R Gobato, A Heidari (2018) Molecular mechanics and quantum chemical study on sites of action of sanguinarine using vibrational spectroscopy based on molecular mechanics and quantum chemical calculations. Malaysian Journal of Chemistry 20: 1-23.

167.A Heidari (2018) Vibrational biospectroscopic studies on anti-cancer nanopharmaceuticals (Part I). Malaysian Journal of Chemistry 20: 33-73.

168.A Heidari (2018) Vibrational biospectroscopic studies on anti-cancer nanopharmaceuticals (Part II). Malaysian Journal of Chemistry 20: 74-117.

169.A Heidari (2018) Uranocene $\left(\mathrm{U}\left(\mathrm{C}_{8} \mathrm{H}_{8}\right)_{2}\right)$ and Bis(Cyclooctatetraene)Iron $\left(\mathrm{Fe}\left(\mathrm{C}_{8} \mathrm{H}_{8}\right)_{2}\right.$ or $\left.\mathrm{Fe}(\mathrm{COT})_{2}\right)$ Enhanced Precatalyst Preparation Stabilization and Initiation (EPPSI) Nano Molecules. Chemistry Reports 1: 1-16.

170.A Heidari (2018) Biomedical systematic and emerging technological study on human malignant and benign cancer cells and tissues biospectroscopic analysis under synchrotron radiation. Glob Imaging Insights 3: 1-7.

171.A Heidari (2018) Deep-level transient spectroscopy and X-Ray Photoelectron Spectroscopy (XPS) comparative study on malignant and benign human cancer cells and tissues with the passage of time under synchrotron radiation. Res Dev Material Sci 7.

172.A Heidari (2018) C70-Carboxyfullerenes nano molecules incorporation into the Nano Polymeric Matrix (NPM) by Immersion of the Nano Polymeric Modified Electrode (NPME) as molecular enzymes and drug targets for human cancer cells, tissues and tumors treatment under synchrotron and synchrocyclotron radiations. Glob Imaging Insights 3: 1-7. 
173.A Heidari (2018) The effect of temperature on Cadmium Oxide ( $\mathrm{CdO}$ ) nanoparticles produced by synchrotron radiation in the human cancer cells, tissues and tumors. International Journal of Advanced Chemistry 6: 140-156.

174.A Heidari (2018) A Clinical and Molecular Pathology Investigation of Correlation Spectroscopy (COSY), Exclusive Correlation Spectroscopy (ECOSY), Total Correlation Spectroscopy (TOCSY), Heteronuclear Single-Quantum Correlation Spectroscopy (HSQC) and Heteronuclear Multiple-Bond Correlation Spectroscopy (HMBC) comparative study on malignant and benign human cancer cells, tissues and tumors under synchrotron and synchrocyclotron radiations using cyclotron versus synchrotron, synchrocyclotron and the Large Hadron Collider (LHC) for delivery of proton and helium ion (charged particle) beams for oncology radiotherapy. European Journal of Advances in Engineering and Technology 5: 414-426.

175. A Heidari (2018) Nano Molecules Incorporation into the Nano Polymeric Matrix (NPM) by Immersion of the Nano Polymeric Modified Electrode (NPME) as molecular enzymes and drug targets for human cancer cells, tissues and tumors treatment under synchrotron and synchrocyclotron radiations. J Oncol Res 1: 1-20.

176. A Heidari (2018) Use of molecular enzymes in the treatment of chronic disorders. Canc Oncol Open Access J 1: 12-15.

177. A Heidari (2018) Vibrational biospectroscopic study and chemical structure analysis of unsaturated polyamides nanoparticles as anti-cancer polymeric nanomedicines using synchrotron radiation. International Journal of Advanced Chemistry 6: 167-189.

178. A Heidari (2018) Adamantane, irene, naftazone and pyridine-enhanced precatalyst Preparation Stabilization and Initiation (PEPPSI) nano molecules. Madridge J Nov Drug Res 2: 61-67.

179.A Heidari (2018) Heteronuclear Single-Quantum Correlation Spectroscopy (HSQC) and Heteronuclear Multiple-Bond Correlation Spectroscopy (HMBC) comparative study on malignant and benign human cancer cells and tissues with the passage of time under synchrotron radiation. Madridge J Nov Drug Res 2: 68-74.

180.A Heidari, R Gobato (2018) A novel approach to reduce toxicities and to improve bioavailabilities of DNA/RNA of Human CancerCells-Containing Cocaine (Coke), Lysergide (Lysergic Acid Diethyl Amide or LSD), $\Delta^{9}$-Tetrahydrocannabinol (THC) [(-)-trans- $\Delta^{9}$ -
Tetrahydrocannabinol], Theobromine (Xantheose), Caffeine, Aspartame (APM) (NutraSweet) and Zidovudine (ZDV) [Azidothymidine (AZT)] as AntiCancer Nano Drugs by coassembly of dual anticancer nano drugs to Inhibit DNA/RNA of human cancer cells drug resistance. Parana Journal of Science and Education 4: 1-17.

181. A Heidari, R Gobato (2018) Ultraviolet Photoelectron Spectroscopy (UPS) and Ultraviolet-Visible (UVVis) spectroscopy comparative study on malignant and benign human cancer cells and tissues with the passage of time under synchrotron radiation. Parana Journal of Science and Education 4: 18-33.

182.R Gobato, A Heidari, A Mitra (2018) The creation of $\mathrm{C}_{13} \mathrm{H}_{20} \mathrm{BeLi}{ }_{2} \mathrm{SeSi}$. The proposal of a bio-inorganic molecule, using $A b$ initio methods for the genesis of a nano membrane. Arc Org Inorg Chem Sci 3.

183.R Gobato, A Heidari (2018) Using the quantum chemistry for genesis of a nano biomembrane with a combination of the elements $\mathrm{Be}, \mathrm{Li}, \mathrm{Se}, \mathrm{Si}, \mathrm{C}$ and H. J Nanomed Res 7: 241-252.

184.A Heidari (2018) Bastadins and BastaranesEnhanced Precatalyst Preparation Stabilization and Initiation (EPPSI) nano molecules. Glob Imaging Insights 3: 1-7.

185.A Heidari (2018) Fucitol, Pterodactyladiene, DEAD or DEADCAT (DiEthyl AzoDiCArboxylaTe), Skatole, the NanoPutians, Thebacon, Pikachurin, Tie Fighter, Spermidine and Mirasorvone Nano Molecules Incorporation into the Nano Polymeric Matrix (NPM) by Immersion of the Nano Polymeric Modified Electrode (NPME) as molecular enzymes and drug targets for human cancer cells, tissues and tumors treatment under synchrotron and synchrocyclotron radiations. Glob Imaging Insights 3: 1-8.

186.E Dadvar, A Heidari (2018) A review on separation techniques of Graphene Oxide (GO)/base on hybrid polymer membranes for eradication of dyes and oil compounds: Recent progress in Graphene Oxide (GO)/base on polymer membranes-related nanotechnologies. Clin Med Rev Case Rep 5: 228.

187.A Heidari, R Gobato (2018) First-Time Simulation of Deoxyuridine Monophosphate (dUMP) (Deoxyuridylic Acid or Deoxyuridylate) and Vomitoxin (Deoxynivalenol (DON)) $((3 \alpha, 7 \alpha)-3,7,15-$ Trihydroxy12,13-Epoxytrichothec-9-En-8-One)-Enhanced Precatalyst Preparation Stabilization and Initiation (EPPSI) Nano Molecules Incorporation into the Nano Polymeric Matrix (NPM) by Immersion of the Nano Polymeric Modified Electrode (NPME) as mo- 
lecular enzymes and drug targets for human cancer cells, tissues and tumors treatment under synchrotron and synchrocyclotron radiations. Parana Journal of Science and Education 4: 46-67.

188. A Heidari (2018) Buckminsterfullerene (Fullerene), Bullvalene, Dickite and Josiphos Ligands Nano Molecules Incorporation into the Nano Polymeric Matrix (NPM) by Immersion of the Nano Polymeric Modified Electrode (NPME) as molecular enzymes and drug targets for human hematology and thromboembolic diseases prevention, diagnosis and treatment under synchrotron and synchrocyclotron radiations. Glob Imaging Insights 3: 1-7.

189.A Heidari (2018) Fluctuation X-Ray Scattering (FXS) and Wide-Angle X-Ray Scattering (WAXS) comparative study on malignant and benign human cancer cells and tissues under synchrotron radiation. Glob Imaging Insights 3: 1-7.

190. A Heidari (2018) A novel approach to Correlation Spectroscopy (COSY), Exclusive Correlation Spectroscopy (ECOSY), Total Correlation Spectroscopy (TOCSY), Incredible Natural-Abundance Double-Quantum Transfer Experiment (INADEQUATE), Heteronuclear Single-Quantum Correlation Spectroscopy (HSQC), Heteronuclear Multiple-Bond Correlation Spectroscopy (HMBC), Nuclear Overhauser Effect Spectroscopy (NOESY) and Rotating Frame Nuclear Overhauser Effect Spectroscopy (ROESY) comparative study on malignant and benign human cancer cells and tissues under synchrotron radiation. Glob Imaging Insights 3: 1-9.

191.A Heidari (2018) Terphenyl-Based Reversible Receptor with Rhodamine, Rhodamine-Based Molecular Probe, Rhodamine-Based Using the Spirolactam Ring Opening, Rhodamine B with Ferrocene Substituent, Calix[4]Arene-Based Receptor, Thioether + Aniline-Derived Ligand Framework Linked to a Fluorescein Platform, Mercuryfluor-1 (Flourescent Probe), N,N'-Dibenzyl-1,4,10,13-Tetraraoxa-7,16-Diazacyclooctadecane and Terphenyl-Based Reversible Receptor with Pyrene and Quinoline as the Fluorophores-Enhanced Precatalyst Preparation Stabilization and Initiation (EPPSI) nano molecules. Glob Imaging Insights 3: 1-9.

192. A Heidari (2018) Nuclear Resonant Inelastic X-Ray Scattering Spectroscopy (NRIXSS) and Nuclear Resonance Vibrational Spectroscopy (NRVS) comparative study on malignant and benign human cancer cells and tissues under synchrotron radiation. Glob Imaging Insights 3: 1-7.

193.A Heidari (2018) Small-Angle X-Ray Scattering (SAXS) and Ultra-Small Angle X-Ray Scattering (USAXS) comparative study on malignant and benign human cancer cells and tissues under synchrotron radiation. Glob Imaging Insights 3: 1-7.

194.A Heidari (2018) Curious Chloride $\left(\mathrm{CmCl}_{3}\right)$ and Titanic Chloride $\left(\mathrm{TiCl}_{4}\right)$-Enhanced Precatalyst Preparation Stabilization and Initiation (EPPSI) nano molecules for cancer treatment and cellular therapeutics. J Cancer Research and Therapeutic Interventions 1: 01-10.

195.R Gobato, MRR Gobato, A Heidari, A Mitra (2018) Spectroscopy and dipole moment of the molecule $\mathrm{C}_{13} \mathrm{H}_{20} \mathrm{BeLi}_{2} \mathrm{SeSi}$ via quantum chemistry using $\mathrm{Ab}$ Initio, Hartree-Fock Method in the Base Set CCpVTZ and 6-311G**(3df, 3pd). Arc Org Inorg Chem Sci 3: 402-409.

196.A Heidari (2018) $C_{60}$ and $C_{70}$-Encapsulating Carbon Nanotubes Incorporation into the Nano Polymeric Matrix (NPM) by Immersion of the Nano Polymeric Modified Electrode (NPME) as molecular enzymes and drug targets for human cancer cells, tissues and tumors treatment under synchrotron and synchrocyclotron radiations. Integr Mol Med 5: 1-9.

197.A Heidari (2018) Two-Dimensional (2D) ${ }^{1} \mathrm{H}$ or Proton NMR, ${ }^{13} \mathrm{C}$ NMR, ${ }^{15} \mathrm{~N}$ NMR and ${ }^{31} \mathrm{P}$ NMR spectroscopy comparative study on malignant and benign human cancer cells and tissues under synchrotron radiation with the passage of time. Glob Imaging Insights 3: 1-8.

198. A Heidari (2018) FT-Raman Spectroscopy, Coherent Anti-Stokes Raman Spectroscopy (CARS) and Raman Optical Activity Spectroscopy (ROAS) comparative study on malignant and benign human cancer cells and tissues with the passage of time under synchrotron radiation. Glob Imaging Insights 3: 1-8.

199.A Heidari (2018) A modern and comprehensive investigation of Inelastic Electron Tunneling Spectroscopy (IETS) and scanning tunneling spectroscopy on malignant and benign human cancer cells, tissues and tumors through optimizing synchrotron microbeam radiotherapy for human cancer treatments and diagnostics: An experimental biospectroscopic comparative study. Glob Imaging Insights 3: 1-8.

200.A Heidari (2018) A hypertension approach to thermal infrared spectroscopy and photothermal infrared spectroscopy comparative study on malignant and benign human cancer cells and tissues under synchrotron radiation with the passage of time. Glob Imaging Insights 3: 1-8.

201.A Heidari (2018) 2-Amino-9-((1S, 3R, 4R)-4-Hydroxy-3-(Hydroxymethyl)-2-Methylenecyclopen- 
tyl)-1H-Purin-6(9H)-One, 2-Amino-9-((1R, 3R, 4R)4-Hydroxy-3-(Hydroxymethyl)-2-Methylenecyclopentyl)-1H-Purin-6(9H)-One, 2-Amino-9-((1R, 3R, 4S)-4-Hydroxy-3-(Hydroxymethyl)-2-Methylenecyclopentyl)-1H-Purin-6(9H)-One and 2-Amino-9-((1S, 3R, 4S)-4-Hydroxy-3-(Hydroxymethyl)-2-Methylenecyclopentyl)-1H-Purin-6(9H)-One-enhanced precatalyst preparation stabilization and initiation nano molecules. Glob Imaging Insights 3: 1-9.

202.A Heidari (2018) Production of Electrochemiluminescence $(\mathrm{ECL})$ Biosensor Using Os-Pd/HfC nanocomposites for detecting and tracking of human gastroenterological cancer cells, tissues and tumors. Int J Med Nano Res 5.

203.A Heidari (2018) Enhancing the raman scattering for diagnosis and treatment of human cancer cells, tissues and tumors using Cadmium Oxide (CdO) nanoparticles. J Toxicol Risk Assess 4.

204.A Heidari (2018) Human malignant and benign human cancer cells and tissues biospectroscopic analysis under synchrotron radiation using anticancer nano drugs delivery. Integr Mol Med 5: 1-13.

205. A Heidari (2018) Analogous nano compounds of the form $\mathrm{M}\left(\mathrm{C}_{8} \mathrm{H}_{8}\right)_{2}$ Exist for $\mathrm{M}=(\mathrm{Nd}, \mathrm{Tb}, \mathrm{Pu}, \mathrm{Pa}$, $\mathrm{Np}, \mathrm{Th}$, and $\mathrm{Yb}$ )-Enhanced Precatalyst Preparation Stabilization and Initiation (EPPSI) nano molecules. Integr Mol Med 5: 1-8.

206. A Heidari (2018) Hadron spectroscopy, baryon spectroscopy and meson spectroscopy comparative study on malignant and benign human cancer cells and tissues under synchrotron radiation. Integr Mol Med 5: 1-8.

207.R Gobato, MRR Gobato, A Heidari (2019) Raman spectroscopy study of the nano molecule $\mathrm{C}_{13} \mathrm{H}_{20} \mathrm{Be}-$ $\mathrm{Li}_{2} \mathrm{SeSi}$ using $\mathrm{Ab}$ initio and Hartree-Fock Methods in the Basis Set CC-pVTZ and 6-311G** (3df, 3pd). International Journal of Advanced Engineering and Science 7: 14-35.

208. A Heidari, R Gobato (2019) Evaluating the effect of anti-cancer nano drugs dosage and reduced leukemia and polycythemia vera levels on trend of the human blood and bone marrow cancers under synchrotron radiation. Trends in Res 2: 1-8.

209.A Heidari, R Gobato (2019) Assessing the variety of synchrotron, synchrocyclotron and LASER radiations and their roles and applications in human cancer cells, tissues and tumors diagnosis and treatment. Trends in Res 2: 1-8.

210.A Heidari, R Gobato (2019) Pros and cons controversy on malignant human cancer cells, tissues and tumors transformation process to benign human cancer cells, tissues and tumors. Trends in Res 2: 1-8.

211.A Heidari, R Gobato (2019) Three-Dimensional (3D) simulations of human cancer cells, tissues and tumors for using in human cancer cells, tissues and tumors diagnosis and treatment as a powerful tool in human cancer cells, tissues and tumors research and anti-cancer nano drugs sensitivity and delivery area discovery and evaluation. Trends in Res 2: 1-8.

212.A Heidari, R Gobato (2019) Investigation of energy production by synchrotron, synchrocyclotron and LASER radiations in human cancer cells, tissues and tumors and evaluation of their effective on human cancer cells, tissues and tumors treatment trend. Trends in Res 2: 1-8.

213.A Heidari, R Gobato (2019) High-Resolution Mapping of DNA/RNA hypermethylation and hypomethylation process in human cancer cells, tissues and tumors under synchrotron radiation. Trends in Res 2: 1-9.

214.A Heidari (2019) A novel and comprehensive study on manufacturing and fabrication nanoparticles methods and techniques for processing Cadmium Oxide ( $\mathrm{CdO}$ ) nanoparticles colloidal solution. Glob Imaging Insights 4: 1-8.

215.A Heidari (2019) A combined experimental and computational study on the catalytic effect of Aluminum Nitride Nanocrystal (AIN) on the polymerization of benzene, naphthalene, anthracene, phenanthrene, chrysene and tetracene. Glob Imaging Insights 4: 1-8.

216.A Heidari (2019) Novel Experimental and ThreeDimensional (3D) multiphysics computational framework of michaelis-menten kinetics for catalyst processes innovation, characterization and carrier applications. Glob Imaging Insights 4: 1-8.

217.A Heidari (2019) The Hydrolysis Constants of Copper (I) $\left(\mathrm{Cu}^{+}\right)$and Copper (II) $\left(\mathrm{Cu}^{2+}\right)$ in aqueous solution as a function of $\mathrm{pH}$ using a combination of ph measurement and biospectroscopic methods and techniques. Glob Imaging Insights 4: 1-8.

218. A Heidari (2019) Vibrational biospectroscopic study of ginormous virus-sized macromolecule and polypeptide macromolecule as mega macromolecules using Attenuated Total Reflectance-Fourier Transform Infrared (ATR-FTIR) spectroscopy and mathematica 11.3. Glob Imaging Insights 4: 1-8.

219.A Heidari (2019) Three-Dimensional (3D) imaging spectroscopy of carcinoma, sarcoma, leukemia, 
lymphoma, multiple myeloma, melanoma, brain and spinal cord tumors, germ cell tumors, neuroendocrine tumors and carcinoid tumors under synchrotron radiation. Glob Imaging Insights 4: 1-9.

220.R Gobato, MRR Gobato, A Heidari (2019) Storm Vortex in the Center of Paraná State on June 6, 2017: A case study. Sumerianz Journal of Scientific Research 2: 24-31.

221. R Gobato, MRR Gobato, A Heidari (2019) Attenuated Total Reflection-Fourier Transform Infrared (ATR-
FTIR) Spectroscopy Study of the Nano Molecule C $13 \mathrm{H} 20$ BeLi 2 SeSi Using ab initio and Hartree-Fock Methods in the Basis Set RHF/CC- pVTZ and RHF/6311G** (3df, 3pd): An experimental challenge to chemists. Chemistry Reports 2: 1-26.

222.R Gobato, MRR Gobato, A Heidari, A Mitra (2019) New Nano-Molecule Kurumi- C 13 H 20 BeLi 2 SeSi/C 13 H 19 BeLi 2 SeSi, and Raman Spectroscopy Using ab initio, Hartree- Fock Method in the Base Set CC-pVTZ and 6-311G** (3df, 3pd). J Anal Pharm Res 8: 1-6. 